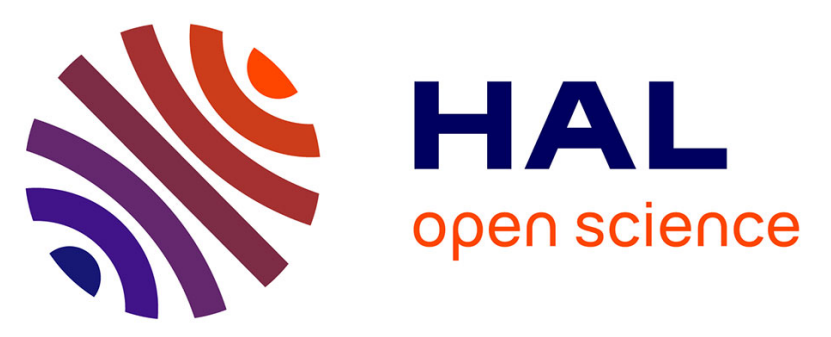

\title{
The interplay of a fault zone and a volcanic reservoir from 3D elasto-plastic models: Rheological conditions for mutual trigger based on a field case from the Andean Southern Volcanic Zone
}

\author{
Javiera Ruz Ginouves, Muriel Gerbault, José Cembrano, Pablo Iturrieta, \\ Felipe Sáez Leiva, Camila Novoa, Riad Hassani
}

\section{To cite this version:}

Javiera Ruz Ginouves, Muriel Gerbault, José Cembrano, Pablo Iturrieta, Felipe Sáez Leiva, et al.. The interplay of a fault zone and a volcanic reservoir from 3D elasto-plastic models: Rheological conditions for mutual trigger based on a field case from the Andean Southern Volcanic Zone. Journal of Volcanology and Geothermal Research, 2021, 418, pp.107317. 10.1016/j.jvolgeores.2021.107317 . hal-03552201

\author{
HAL Id: hal-03552201 \\ https://hal.science/hal-03552201
}

Submitted on 2 Feb 2022

HAL is a multi-disciplinary open access archive for the deposit and dissemination of scientific research documents, whether they are published or not. The documents may come from teaching and research institutions in France or abroad, or from public or private research centers.
L'archive ouverte pluridisciplinaire HAL, est destinée au dépôt et à la diffusion de documents scientifiques de niveau recherche, publiés ou non, émanant des établissements d'enseignement et de recherche français ou étrangers, des laboratoires publics ou privés. 


\title{
The interplay of a fault zone and a volcanic reservoir from 3D elasto-plastic models: Rheological conditions for mutual trigger based on a field case from the Andean Southern Volcanic Zone
}

\author{
J. Ruz Ginouves ${ }^{a, b}, *$, M. Gerbault ${ }^{c}$, J. Cembrano ${ }^{a, b}$, P. Iturrieta ${ }^{d}$, F. Saez Leiva ${ }^{a, b}$, C. Novoa ${ }^{c}$, R. Hassani ${ }^{\text {e }}$ \\ a Department of Structural and Geotechnical Engineering, Pontificia Universidad Católica de Chile, Santiago, Chile \\ ${ }^{\mathrm{b}}$ Andean Geothermal Centre of Excellence (CEGA), Universidad de Chile, Santiago, Chile \\ c GET/UMR5563 (UPS, CNRS, IRD, CNES); Obs. Midi-Pyrénées, Université P. Sabatier, Toulouse, France \\ ${ }^{\mathrm{d}}$ Helmholtz Centre Potsdam, GFZ German Research Centre for Geosciences, Potsdam, Germany. \\ e Géoazur/UMR7329 (UNSA,CNRS,IRD,OCA) Les Lucioles 1, Sophia Antipolis, 06560 Valbonne, France
}

\section{ARTICLE INFO}

Article history:

Received 13 January 2021

Received in revised form 29 April 2021

Accepted 12 June 2021

Available online xxx

\section{Keywords}

Elasto-plastic deformation

Magmatic reservoirs

Crustal fault zones

Brittle failure

Dilatational induced porosity

Volcano-tectonics

Geothermal systems

\begin{abstract}
A B S T R A C T
The Southern Andes margin hosts active and fossil volcanic, geothermal, and mineralized systems documenting intense geofluid migration through the crust. Fluid flow is also spatially associated with crustal faults that accommodate the bulk deformation arising from oblique plate convergence. Although recognized, the precise local mechanical interaction between faults and crustal reservoirs is yet to be better understood. Here we present 3D numerical models of a magmatic reservoir and a fault zone set about $4 \mathrm{~km}$ apart, inspired by the Tatara-San Pedro volcanic complex in the Southern Volcanic Zone $\left(\sim 36^{\circ} \mathrm{S}\right)$, which displays a geothermal field and a margin-parallel dextral active fault zone constrained by crustal seismicity and published magnetotelluric profiles. We investigate elasto-plastic deformation and stress patterns in the intermediate bedrock space between the reservoir and the fault zone and test how shear stress, volumetric strain, and plastic strain develop. We also test the potential of enabling brittle failure of their counterpart by imposing either (1) a strike-slip displacement along the fault zone, or (2) a magmatic overpressure at the cavity walls. Parametric tests of Young's modulus and frictional strength provide the conditions for macro-scale brittle failure and show the development of diffuse domains of dilatational strain of the order of $10^{-5}-10^{-3}$ in the intervening bedrock. This dilatation is a proxy to the opening of voids or volumetric cracking in the bedrock, which tends to increase porosity and permeability allowing over-pressurized geofluids to migrate within these domains. Our results show that a minimum of $60 \mathrm{~m}$ of fault displacement is required to trigger brittle failure of an upper crustal cavity if the bedrock is stiff, whereas, for a more compliant bedrock, more than $100 \mathrm{~m}$ of localized slip motion is required. This implies that it is rather the accumulated effect of repeated crustal fault displacement that potentially favors fluid pathways upwards, rather than a single seismic event. On the other hand, a minimum of 7.5 MPa of fluid overpressure is required for a mid-crustal cavity (12 km depth) to trigger brittle failure of the fault zone. This threshold overpressure increases up to $50 \mathrm{MPa}$ when the cavity is shallower ( $5 \mathrm{~km}$ depth). Our results show that in general, shallow reservoirs must be very close to fault zones (less than 1-2 km apart) to reactivate them. The models show that localized strike-slip tectonics and magma intrusions build a dilatational stress field at the scale of several kilometers, that promotes fluid pathways to the surface. Further combining this interaction with the regional transpressional stress field may explain observations of transient fluid pathways on seemingly independent timescales along the Andean margin.
\end{abstract}

\section{Introduction and statement of the problem}

The nature of the interplay between tectonics and volcanism has been addressed by many authors over the last decades (e.g. Nakamura, 1977; Cembrano and Lara, 2009; Acocella et al., 2018).

\footnotetext{
* Corresponding author at: Department of Structural and Geotechnical Engineering, Pontificia Universidad Católica de Chile, Santiago, Chile. E-mail address: jnruz@uc.cl (J. Ruz Ginouves)
}

The most common approach to date has been a combination of field structural geology of basement rocks, paleo stress reconstructions from fault-slip data and dilatational fractures (ie. veins and dykes), morphometric analyses of volcanic features (e.g. Lavenu and Cembrano, 1999; Brogi et al., 2010; Pérez-Flores et al., 2016; Sielfeld et al., 2017; Tibaldi and Bonali, 2017), as well as laboratory studies of magma-tectonic interactions (Galland et al., 2018, and references therein). Although these methodologies have been successful in identifying feedback relationships between crustal deformation and magma migration in a variety of tectonic settings, a precise understanding of 
the kilometric scale stress and strain field associated with both localized deformation and fluid transfer towards the surface, remains poorly constrained in terms of the identification of key mechanical properties and geometrical arrangement.

Active and fossil volcanic-geothermal systems on Earth have been spatially associated with major fault systems that accommodate and compartmentalize bulk deformation (e.g. McCaffrey et al., 2000; Cembrano and Lara, 2009; Rowland and Simmons, 2012). Fault-fracture networks induced by deformation may provide transient pathways for geofluids to percolate, ascend or be stored within the crust (e.g. Hill, 1977), and conversely, fluid percolation processes may enhance deformation and promote earthquakes (e.g. Pearce et al., 2020). In either case, the rock mass's bulk permeability is continually modified and may increase in several orders of magnitude to that of the surrounding bedrock. This aspect has been addressed in tectonically active geothermal environments such as in the Taupo Volcanic Zone (e.g. Rowland and Sibson, 2004), the Larderello geothermal area (e.g. Liotta and Brogi, 2020), the Tolhuaca geothermal area (Pérez-Flores et al., 2017), and in exhumed fossil fault systems (e.g. Atacama Fault System; e.g. Gomila et al., 2016). Nonetheless, it remains difficult to identify the mechanical interaction of structural discontinuities and seismically active fault zones, and adjacent geofluid reservoirs.

Numerical modelling efforts on understanding the latter mechanical interaction have been conducted for case studies in different tectonic settings. For instance, Simakin and Ghassemi (2010) examined the role of a fault zone overriding an inflating magma cavity on stress distribution, failure, and dyking through 2D numerical simulations of a viscoelastic medium. The role of the elastic properties of a heterogeneous and anisotropic crust has been investigated by Karaoglu et al. (2016) in the Karliova Triple Junction (Turkey) under different tectonic loading conditions, while Zhan et al. (2019) applied 3D numerical models to test the effect of a preexisting weak fault zone on the pressurization of the magmatic system and failure development with Mohr-Coulomb yield criterion. However, the factors that drive the interaction between magma reservoirs and fault systems over intermediate time scales are still to be better understood in a general framework.

In this paper, we tackle the problem of the first-order interplay between a strike-slip fault zone and a magma reservoir with three-dimensional (3D) numerical experiments, inspired by a specific volcanic system in the Andean Southern Volcanic Zone (SVZ). We aim to understand their possible connection and some of the fundamental mechanical constraints driving their local interaction at time scales possibly larger than individual seismogenic events. Considering this intermediate time scale may help explain field observations of localized or diffuse deformation associated with hydrothermal and magmatic fluid flow. We do not intend to use numerical models to match geological observations, but rather to test which key variables play a fundamental role in the way magma pressure and active faulting interact. By using elasto-plastic rheology, our numerical models can show domains with diffuse or localized, contractional, or dilatational strain, which in turn give insight on the potential location of pervasive magmatic fluid percolation, accumulation, or blockage, as well as on the potential triggering of seismicity.

\section{Field case from the Chilean margin: the Tatara San Pedro Pellado volcanic complex}

The Chilean margin exposes a variety of volcano-tectonic settings within a regional bulk transpressional subduction margin that is characterized by an oblique convergence between the Nazca and South American plates over the last $20 \mathrm{Ma}$ (Pardo-Casas and Molnar, 1987). Previous work along the SVZ over the last decades showed that dextral transpressional deformation dominates from ca. $34^{\circ} \mathrm{S}$ to $46^{\circ} \mathrm{S}$, at least from the Pliocene (Cembrano et al., 1996). The region from $34^{\circ} \mathrm{S}$ to $37^{\circ} \mathrm{S}$ is dominated by margin-parallel Miocene-Pliocene margin- parallel folds and reverse faults developed on Meso-Cenozoic volcano-sedimentary units (e.g. Mescua et al., 2016; Giambiagi and Ramos, 2002) and by active, less-well exposed NNE to NE-striking dextral strike-slip faults (Tapia et al., 2015; Cardona et al., 2018; Piquer et al., 2018) and NW-striking faults (Pearce et al., 2020; Sielfeld et al., 2019b). In turn, south of $37^{\circ} \mathrm{S}$, the intra-arc $\sim$ NNE-striking dextral strike-slip Liquiñe Ofqui fault system (LOFS) accommodates a significant portion of the bulk transpressional deformation (Stanton-Yonge et al., 2016; Iturrieta et al., 2017). WNWand ENE-striking Andean Transverse Faults (ATF) are found all along the SVZ and have been genetically associated with stratovolcanoes and minor eruptive centers (e.g. Lara et al., 2006; Cembrano and Lara, 2009; Piquer et al., 2018) (Fig. 1a). Recent studies using local seismic networks (Pearce et al., 2020; Sielfeld et al., 2019a) show that WNW and ENE-striking ATF are seismogenic and may be linked to fluid migration in the crust, consistent with long-term geological observations.

We selected a representative case study in the SVZ (Fig. 1b) for which regional to local scale structural geology, crustal seismicity, and conductivity structure of the lithosphere are known from the literature. The Tatara-San Pedro Volcanic Complex (TSPVC) consists of an Early Pleistocene-Holocene group of composite volcanoes, lava flows, dyke swarms, and minor volcanic vents (Davidson et al., 1988). The main volcanic edifices, the Tatara-San-Pedro and the Pellado-San Pablo summits (Fig. 1b), are aligned in an ENE orientation and contain more than 20 eroded minor eruptive vents on their flanks, extending to the east over a lava plateau (Singer et al., 1997). The volcanic products include lava flows and pyroclastic deposits with compositions ranging from basalts to rhyolites (Singer et al., 1997). ENE-striking sub-vertical dykes have been mapped on the northern, eastern, and southern sides of the volcanic complex and are interpreted as coeval with Late Pleistocene-recent oblique-slip tectonics (Singer et al., 1997; Sielfeld et al., 2019b; Ruz et al., 2020).

Active tectonic features in this segment of the volcanic arc include both margin parallel strike-slip faults and ATF. Approximately $10 \mathrm{~km}$ to the southwest of the Tatara-San Pedro volcano, the NNE-striking Melado fault is constrained by $>600$ aftershocks and the dextral strike-slip moment tensor of a Mw 6.0 crustal earthquake in 2012 (from NEIC and GCMT catalogues; Cardona et al., 2018). ATF are represented by NW-striking Los Cóndores Fault Zone and the NE-ENE-striking Tatara Damage Zone (TDZ) respectively and are constrained by detailed structural mapping (Sielfeld et al., 2019b, Fig. 1b). The TDZ is a long-lived structural anisotropy of cross-cutting mesoscale ENE-WNW-striking transtensional oblique-slip faults and dykes that form a graben-like geometry developed before and during the construction of the TSPVC.

Magnetotelluric surveys in this region show upper crustal conductive anomalies consistent in location with the TSPVC and the Mariposa Geothermal System (MGS), a high enthalpy geothermal reservoir with inferred fluid temperatures of up to $292^{\circ} \mathrm{C}$ (Hickson et al., 2011; Reyes-Wagner et al., 2017). Hot springs are associated with the edges of the high conductivity body. The MGS consists of a clay alteration cap at $\sim 500 \mathrm{~m}$ depth, that marks the upper boundary of the active system and a low resistivity body at a depth of $2 \mathrm{~km}$, that is interpreted as a magma intrusion acting as the heat source to the system. The MGS and the TSPVC have been constructed on top of the aforementioned TDZ (Sielfeld et al., 2019b), a structure that has acted as a permeable path for fluid migration and storage.

Here, we target the genetic link and interplay between magmatic pressurization from mid-crustal depths, with the seismic activity of a crustal fault zone, represented by the Melado fault zone, and the development of the Mariposa geothermal field. 

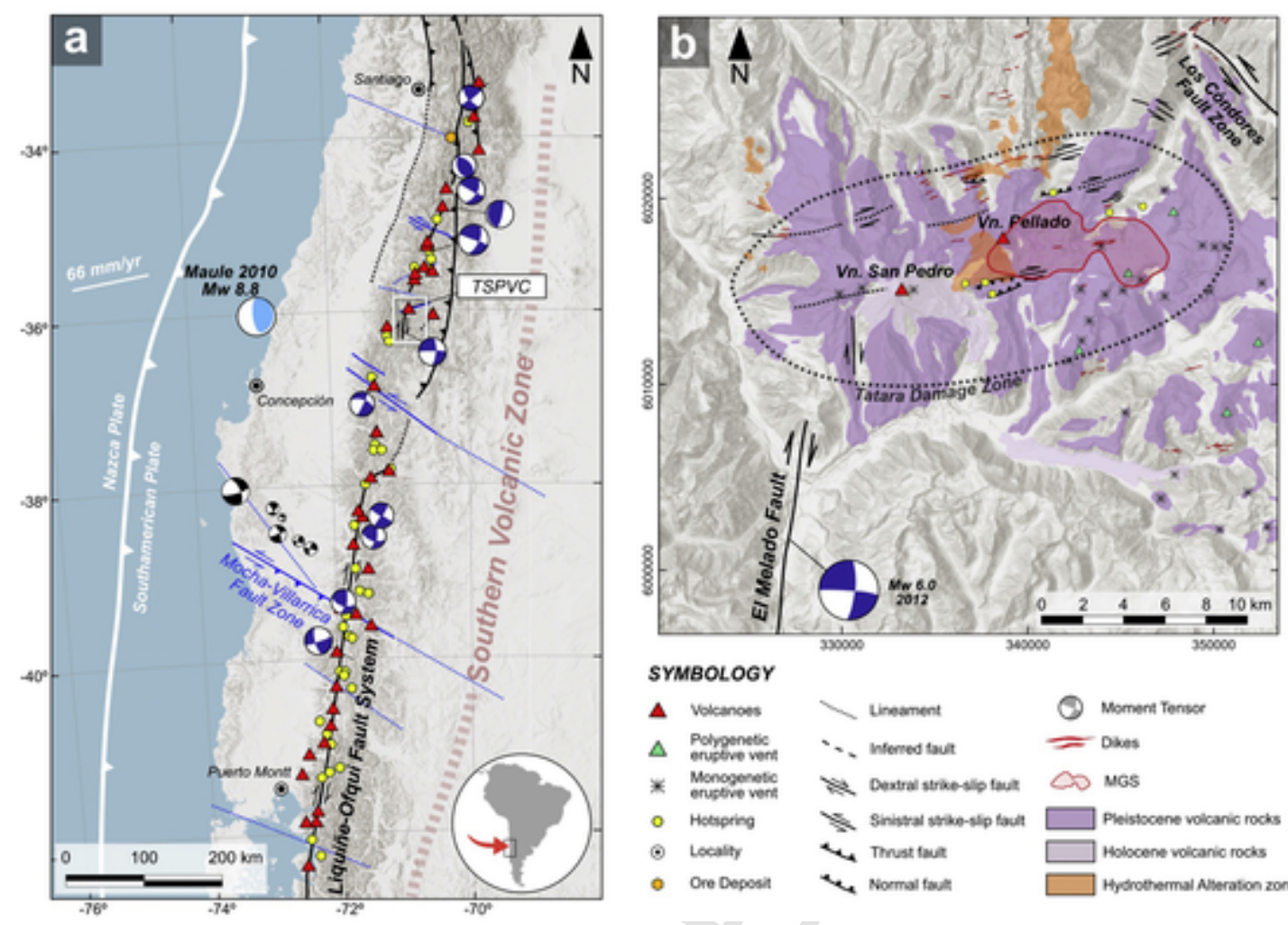

SYMBOLOGY

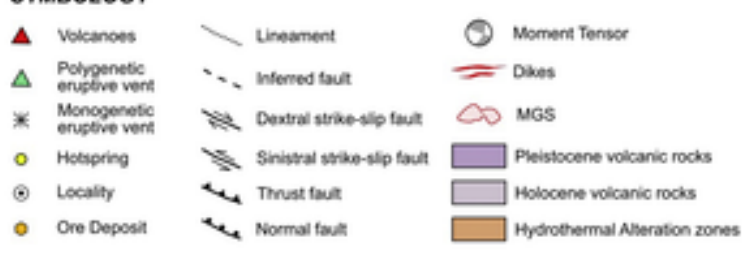

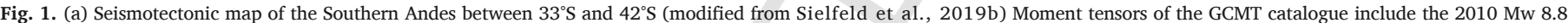

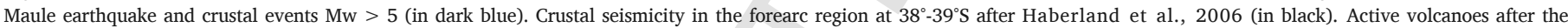

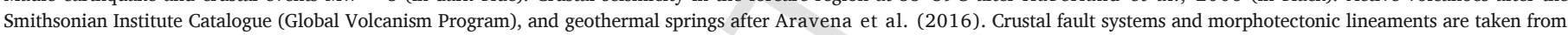

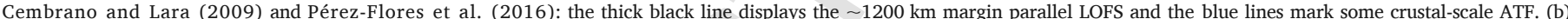

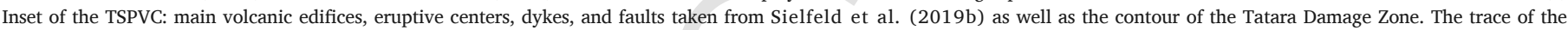

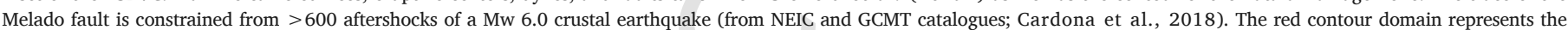
Mariposa Geothermal System (after Hickson et al., 2011). (For interpretation of the references to colour in this figure legend, the reader is referred to the web version of this article.)

\section{Numerical approach, setup, and experiments}

\subsection{Modelling background}

Both analogue modelling and numerical simulations have been used to understand the mechanical processes governing volcanic plumbing systems in different tectonic settings (see reviews by Acocella, 2014, Kavanagh et al., 2018, or Galland et al., 2018). For instance, analogue experiments have been used to show how over-pressurized fluids may be expelled upwards within compressional (e.g. Galland et al., 2007; Tibaldi, 2005) or strike-slip settings (Holohan et al., 2008). Numerical modelling using the theory of elasticity has shown how an inflating elliptical domain may generate heterogeneous stress and deformation within layers of variable Young's modulus under extensional (e.g. Gudmundsson, 2006), compressional, or strike-slip tectonic settings (e.g. Karaoglu et al., 2018; Le Corvec et al., 2015).

Classical analytical solutions of an inflating spherical magmatic cavity embedded in an elastic half-space predict that the stress field decays by $1 / r^{3}$ with radial distance $r$ to an idealized spherical cavity and that stresses rotate by $90^{\circ}$ between the roof of the cavity wall and the overlying top free surface (Jeffery, 1921). Failure of the surrounding bedrock, as a response to the variations in the internal pressure of the cavity, occurs through combinations of shear and tensile failure (e.g. Rozhko et al., 2007; Gerbault, 2012; Abdelmalak et al., 2012; Grosfils et al., 2015), which is represented as localized deformation via dyke opening or shear zones that could potentially act as magmatic pathways upwards. Gerbault et al. (2018) studied shear failure patterns in 3D depending on the geometry of an inflating pressure cavity and discussed how domains of dilation at the edges of an oblate reser- voir may open the bedrock's porosity and favor lateral fluid migration, a mechanism also proposed by Zhan et al. (2019) for the Laguna del Maule for instance. Moreover, elasto-plastic modelling studies show that shear failure can occur at the tip of an intruding over-pressurized sill, both with analogue experiments (Schmiedel et al., 2019) and numerical approaches (Souche et al., 2019).

Furthermore, Coulomb Stress Change (CSC) modelling approaches (e.g. King et al., 1994) have demonstrated how fault systems can either be triggered or locked based on the modification of the stress field induced by a localized slip motion. CSC has also been used to study the short time scale coupling between crustal earthquakes and magmatic events. For example, Díez et al. (2005) and Gregg et al. (2018) propose that the 1999 and 2005 eruptions of Cerro Negro and Sierra Negra volcanoes were triggered by the static stress changes induced by $\sim \mathrm{Mw}$ 5 earthquakes on neighboring faults. On the other hand, Ebmeier et al. (2016) show that with InSAR and CSC modelling that earthquakes triggered during an unrest period can also inhibit an otherwise imminent eruption.

Fluid overpressure reduces the normal stress acting along or within a relatively weak domain, effectively reducing its strength and thus enabling brittle failure (Sibson, 1994). Brittle failure may be seismogenic or not, and a standard first-order approximation of its occurrence consists in using theoretical plasticity, which describes the development of localized deformation once at a shear stress threshold. At the crustal arc scale, Iturrieta et al. (2017) showed with elasto-plasticity how stressing a system of weak fault zones enables to focus either dilatational or contractional deformation at their intersection points and along orientations consistent with observed volcanic complexes along the SVZ. 
The modelling approach taken here focuses on intermediate time and length scales (several kilometers), over which the accumulation of shear motion along a fault zone or of a pressure load from an inflating magma source, incrementally modifies the stress field to promote localized or diffuse deformation. For this purpose, we use the numerical code Adeli (Chéry et al., 2001), a 3D Finite Element Method (FEM) based on the dynamic relaxation approach developed by Cundall and Board (1988). As an advantage upon other numerical methods, Adeli deals with the initiation and development of plastic domains, which is what is needed here to identify both elastic and plastic responses to progressively applied loads. Adeli has been widely used to model a variety of geodynamic and tectonic settings such as large-scale deformation in subduction zones (Cerpa et al., 2015), intraplate crustal fault zones (Chéry et al., 2001), and deformation around over pressurized reservoirs (Gerbault et al., 2018; Novoa et al., 2019). Detailed equations and resolution method can be found in these references and in Appendix A. Specifically, here we use the Drucker Prager yield criterion, where an initially elastic medium yields plastically when the yield stress envelope is reached for shear failure (mode II, $F_{D P}$ ) or tensile failure (mode I, $F_{T}$ ), cf. Appendix A:

$$
\begin{aligned}
F_{D P}(\sigma)= & J_{2}(\sigma)+\frac{6 \sin \varphi}{(3-\sin \varphi)} I_{1}(\sigma) \\
& -\frac{6 C \sin \varphi}{(3-\sin \varphi)(\tan \varphi)} \\
= & 0,
\end{aligned}
$$

$F_{T}(\sigma)=I_{1}(\sigma)-T=0$,

where $\varphi$ is the friction angle, $C$ is cohesion, $T$ is tensile strength, and $I_{1}(\sigma)$ and $J_{2}(\sigma)$ are the first and second invariants of the stress tensor $\sigma$.

\subsection{Model setup and experiments}

To test the mechanical interaction between a weak fault zone and an over pressurized cavity, we choose to synthetically mimic the TSPVC field setting by considering (a) a rectangular-shape fault zone, and (b) an ellipsoidal magmatic cavity (Fig. 2).

a. The fault zone is assimilated with the Melado fault: a NNE-striking dextral strike-slip fault, whose geometry and kinematics are constrained by shallow seismicity (Cardona et al., 2018). More than
600 aftershocks of a Mw 6.0 earthquake describe a $\sim 12 \mathrm{~km}$ long, steeply dipping fault extending down to about $12 \mathrm{~km}$ depth. Thus, the modelled fault zone forms a parallelepiped of dimensions $12 \times 12 \times 0.4 \mathrm{~km}^{3}$ (length, depth, width).

b. The dimension of the cavity is constrained by published regional and local MT studies (Hickson et al., 2011; Reyes-Wagner et al., 2017) and is here modelled as an E-W elongated cavity located at either shallow or deep depths. In the shallow case, the cavity has semi axis dimensions of $3.5 \times 2.5 \times 2 \mathrm{~km}^{3}$ (X, Y, Z directions) and is centered at $6 \mathrm{~km}$ depth, consistent with MT anomaly C2 (Fig. 5 in Reyes-Wagner et al., 2017). In the deep case it has dimensions $8 \times 8 \times 3 \mathrm{~km}^{3}$ and is centered at $10 \mathrm{~km}$ depth, consistent with anomaly C1 (Fig. 5 in Reyes-Wagner et al., 2017). In both cases, the fault zone is kept in the same position, thus the minimum distance between fault and cavity is ca. 4 and $2 \mathrm{~km}$ in each configuration. This critical distance will have an effect in the onset of failure and is further described in Appendix D.

Once these reservoir and fault geometries are fixed, we test two end-member configurations to evaluate our mechanical problem (Fig. 2):

1. Configuration 1 simulates an active strike-slip fault, such as the NNE-striking Melado fault of our field study. Increasing fault displacement $D D$ (constant velocity $V$ applied on the eastern side of the meshed fault zone) induces deformation in the surrounding rock volume, which in turn potentially affects the mechanical stability of the magma-filled cavity. Here we explore for which $D D$ could the reservoir fail.

2. Configuration 2 simulates a progressively increasing over pressure $(D P)$ at the walls of a magma-filled cavity. This overpressure deforms the surrounding rock volume and potentially triggers brittle displacement along the nearby crustal fault. Here we explore for which $D P$ could the fault zone fail.

The meshed domain consists of a 3D block of $60 \mathrm{~km}$ in both horizontal $\mathrm{X}$ and $\mathrm{Y}$ directions (positive $\mathrm{Y}$ is roughly oriented northward), and $40 \mathrm{~km}$ deep (negative downwards), with mesh resolution increasing from $200 \mathrm{~m}$ at the cavity and fault walls, to $5 \mathrm{~km}$ at the borders of the model domain (Fig. 2). All models are initialized at isotropic lithostatic stress equilibrium (weight of the overburden rock), considering a
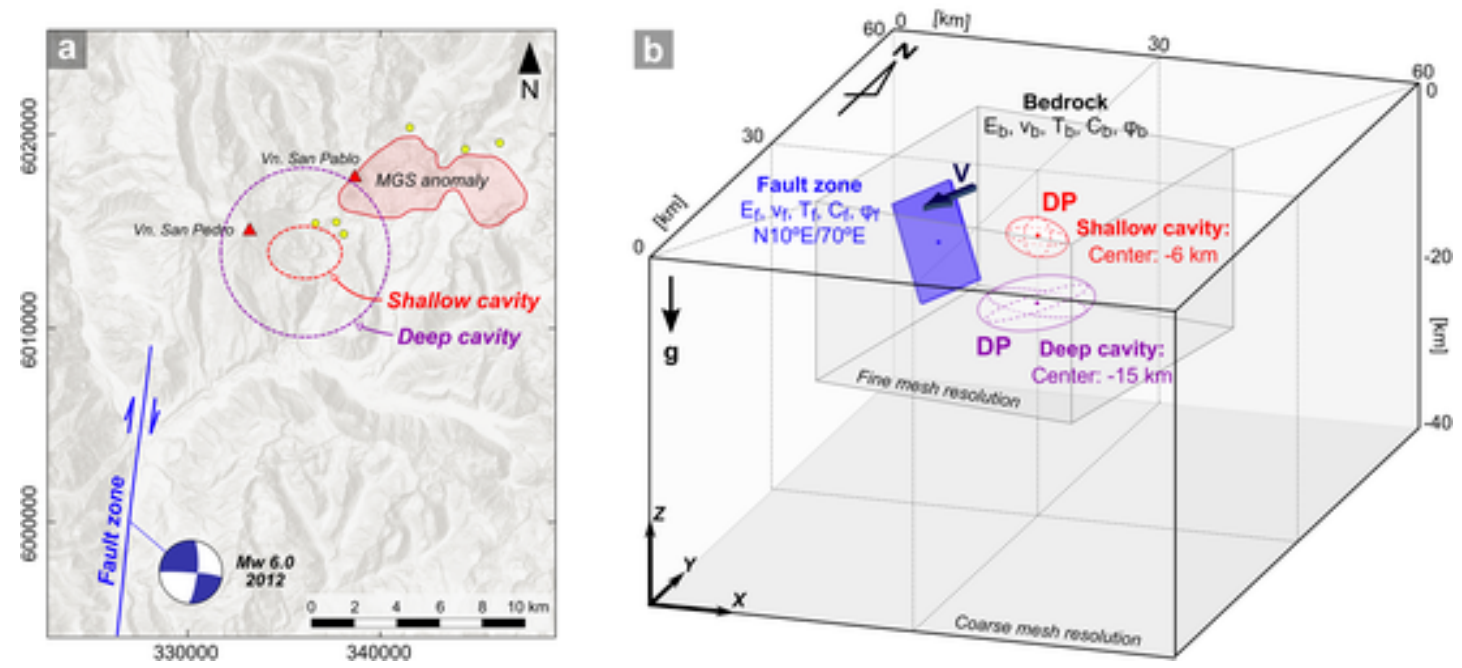

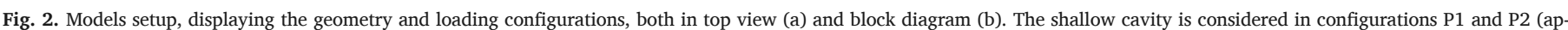

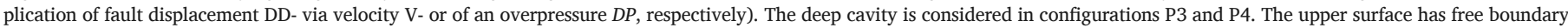

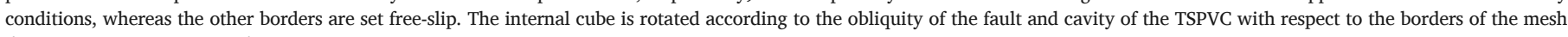
domain (arrow pointing north). 
rock density $(\rho)$ of $2800 \mathrm{~kg} / \mathrm{m}^{3}$ and gravity $(g)$ set to $10 \mathrm{~m} / \mathrm{s}^{2}$. Here, we have chosen not to consider the influence of the long-term regional transpressive stress field, in order to first understand the first-order local interplay between the fault zone and cavity. Nonetheless, we acknowledge that the regional stress field will additionally contribute and have an effect on the resulting failure threshold values and on stress and strain magnitudes (cf. discussion section 6.5).

To reproduce a broad panel of possible deformation patterns, more than 100 model cases were evaluated, where elasto-plastic properties were tested in the following range of values, for both the bedrock (subscript ${ }_{b}$ ) and fault zone domains (subscript ${ }_{\mathrm{f}}$ ): Young's modulus $(E)$ from 1 to $40 \mathrm{GPa}$, Tensile strength $(T)$ and Cohesion $(C)$ between 1 and $20 \mathrm{MPa}$, friction between $0^{\circ}$ and $5^{\circ}$ for the fault zone $\left(\varphi_{f}\right)$ and between $1^{\circ}$ and $20^{\circ}$ for the bedrock $\left(\varphi_{b}\right)$. The chosen range of parameters is discussed in Section 6.2.

Because previous studies have already shown the stress and deformation pattern induced in elasto-plastic media in 2D or 3D by strike-slip faults (e.g. Chéry et al., 2001), or by inflating reservoir cavities (e.g. Simakin and Ghassemi, 2010, Gerbault et al., 2012, Gerbault et al., 2018), the models described below aim at synthesizing key results. Therefore we discuss and illustrate only selected tests that produce the most significant results. In our description of these results, we will often abusively refer to the magnitude of the second invariant of the deviatoric stress $J_{2}$ as simply the shear stress. Figures and comments refer also to dilatation or constriction $\Delta$, which represents the trace of the first invariant of the deviatoric strain tensor $\varepsilon$, and to plastic strain $\varepsilon_{\mathrm{p}}$, which represents magnitudes of the second invariant of the deviatoric plastic strain. The strain tensor is actually defined as the sum of the elastic and plastic strain (cf. Appendix A).

\section{Modelling results}

The main rheological parameters and results for a selection of 32 models, are summarized in Tables 1 and 2 . These models comprise two geometrical configurations, shallow and deep cavity locations, for each loading condition: applied fault displacement (Section 4.1) or applied cavity overpressure (Section 4.2 ).
We may a priori anticipate some of these key results with simple analytical considerations:

1. Firstly, considering the elastic behavior of the bedrock domain, where stress is proportional to Young's modulus and strain (Hooke's law $\sigma=E \cdot \varepsilon$ in one dimension), a stress source will spread around and produce a smaller volumetric deformation through the bedrock if the Young's modulus increases. Several models below will illustrate this influence of the Young's modulus on the strain pattern.

2. Secondly, our models consider gravity, thus, for rock failure to occur in mode I or in mode II, the yield stress threshold $\left(J_{2}\right)$ depends on the mean stress ( $I_{1}$, definitions in Appendix A), which includes the lithostatic stress. This promotes shear failure over tensile failure especially at depths greater than about $2 \mathrm{~km}$ (cf. Grosfils et al., 2015; Gerbault, 2012). Because we are interested in identifying failure patterns at depths greater than $2 \mathrm{~km}$, the tensile failure threshold $T$ will thus not play a significant role. Hence in our models below we do not discuss this secondary influence of $T$, which was fixed to low values between 1 and $3 \mathrm{MPa}$.

3. Thirdly, the friction angle will have a major control on failure development. Considering the Drucker-Prager yield criterion (Appendix eq. A1.3), the friction angle defines the slope of the failure envelope. Hence, a higher friction angle will allow for a higher shear stress before failure. Its influence is commented below with different test cases.

\subsection{Configuration 1: applied fault displacement (P1 and P4 cases)}

A total of $200 \mathrm{~m}$ of displacement $(D D)$ is applied in the form of a continuous velocity (V) along the fault zone's easternmost (hanging) wall, simulating a dextral displacement propagating southward. Here, we seek to find the amount of $D D$ required to promote 'failure' on the walls of a shallow and deep cavity, which refers to when plastic yield occurs at the cavity walls (visualized with the plastic shear strain $\varepsilon_{\mathrm{p}}$ ). We observe that an imposed localized displacement on the fault in-

Table 1

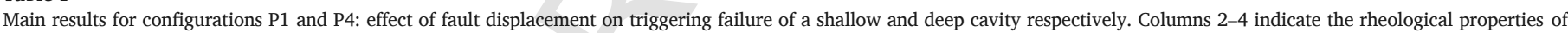

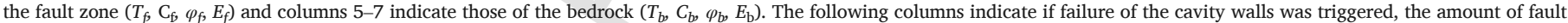

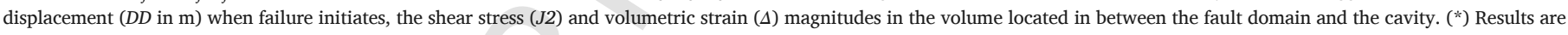
presented for the indicated accumulated amount of fault displacement $(D D)$.

\begin{tabular}{|c|c|c|c|c|c|c|c|c|c|c|c|c|c|}
\hline & Config & $\begin{array}{l}T_{f} \\
(\mathrm{MPa})\end{array}$ & $\begin{array}{l}\mathrm{C}_{\mathrm{f}} \\
(\mathrm{MPa})\end{array}$ & $\varphi_{f}$ & $\begin{array}{l}E_{f} \\
(\mathrm{GPa})\end{array}$ & $\begin{array}{l}T_{b} \\
(\mathrm{MPa})\end{array}$ & $\begin{array}{l}C_{b} \\
(\mathrm{MPa})\end{array}$ & $\varphi_{b}$ & $\begin{array}{l}E_{b} \\
(\mathrm{GPa})\end{array}$ & $\begin{array}{l}\text { Cavity } \\
\text { Failure }\end{array}$ & $\begin{array}{l}D D \\
(\mathrm{~m}) \text { at } \\
\text { failure } \\
\left({ }^{*}\right)\end{array}$ & $\begin{array}{l}\text { Shear } \\
\text { Stress } \\
(\mathrm{MPa})\end{array}$ & $\begin{array}{l}\text { Volumetric } \\
\text { strain }\end{array}$ \\
\hline \multirow[t]{13}{*}{ Shallow Cavity (P1) } & $\mathrm{P} 1-1$ & 2 & 5 & 1 & 40 & 2 & 5 & 15 & 40 & Yes & $160 \mathrm{~m}$ & $>50 \mathrm{MPa}$ & $>1 \times 10^{-4}$ \\
\hline & P1-A & 2 & 5 & 1 & 25 & 2 & 5 & 15 & 25 & No & $200 \mathrm{~m}$ & $>40 \mathrm{MPa}$ & $>3 \times 10^{-4}$ \\
\hline & $\mathrm{P} 1-2$ & 3 & 5 & 1 & 10 & 3 & 5 & 15 & 10 & No & $200 \mathrm{~m}$ & $>40 \mathrm{MPa}$ & $>3 \times 10^{-4}$ \\
\hline & P1-3 & 2 & 5 & 1 & 1 & 2 & 5 & 15 & 1 & No & $200 \mathrm{~m}$ & $>5 \mathrm{MPa}$ & $>5 \times 10^{-4}$ \\
\hline & P1-4 & 3 & 5 & 0 & 40 & 3 & 5 & 5 & 40 & Yes & $100 \mathrm{~m}$ & $>20 \mathrm{MPa}$ & $>6 \times 10^{-5}$ \\
\hline & P1-B & 2 & 5 & 1 & 25 & 2 & 5 & 5 & 25 & Yes & $155 \mathrm{~m}$ & $>20 \mathrm{MPa}$ & $>1 \times 10^{-4}$ \\
\hline & P1-C & 2 & 5 & 1 & 10 & 2 & 5 & 5 & 10 & No & $200 \mathrm{~m}$ & $>20 \mathrm{MPa}$ & $>2 \times 10^{-4}$ \\
\hline & P1-5 & 2 & 5 & 1 & 1 & 3 & 5 & 5 & 1 & No & $120 \mathrm{~m}$ & $>8 \mathrm{MPa}$ & $>8 \times 10^{-4}$ \\
\hline & P1-6 & 2 & 5 & 1 & 40 & 2 & 5 & 1 & 40 & Yes & $60 \mathrm{~m}$ & $>12 \mathrm{MPa}$ & $>2 \times 10^{-5}$ \\
\hline & P1-7 & 2 & 5 & 1 & 20 & 2 & 5 & 1 & 20 & Yes & $110 \mathrm{~m}$ & $>12 \mathrm{MPa}$ & $>5 \times 10^{-5}$ \\
\hline & P1-8 & 2 & 5 & 1 & 10 & 2 & 5 & 1 & 20 & Yes & $120 \mathrm{~m}$ & $>11 \mathrm{MPa}$ & $>3 \times 10^{-5}$ \\
\hline & P1-9 & 3 & 5 & 1 & 5 & 3 & 5 & 1 & 10 & No & $50 \mathrm{~m}$ & $>10 \mathrm{MPa}$ & $>6 \times 10^{-5}$ \\
\hline & $\mathrm{P} 1-10$ & 2 & 5 & 1 & 1 & 2 & 5 & 15 & 10 & No & $200 \mathrm{~m}$ & $>40 \mathrm{MPa}$ & $>5 \times 10^{-4}$ \\
\hline \multirow[t]{6}{*}{ Deep Cavity (P4) } & P4-1 & 2 & 5 & 1 & 40 & 3 & 5 & 15 & 40 & No & $200 \mathrm{~m}$ & $20 \mathrm{MPa}$ & $5 \times 10^{-5}$ \\
\hline & P4-2 & 2 & 5 & 1 & 1 & 3 & 5 & 15 & 1 & No & $200 \mathrm{~m}$ & $10 \mathrm{MPa}$ & $>4 \times 10^{-4}$ \\
\hline & P4-3 & 2 & 5 & 0 & 40 & 2 & 5 & 2 & 40 & No & $114 \mathrm{~m}$ & $>8 \mathrm{MPa}$ & $>1 \times 10^{-5}$ \\
\hline & P4-4 & 2 & 5 & 1 & 20 & 3 & 5 & 5 & 20 & No & $142 \mathrm{~m}$ & $>5 \mathrm{MPa}$ & $>1 \times 10^{-5}$ \\
\hline & P4-5 & 1 & 2 & 0 & 5 & 3 & 5 & 5 & 10 & No & $133 \mathrm{~m}$ & $>5 \mathrm{MPa}$ & $>3 \times 10^{-5}$ \\
\hline & P4-6 & 2 & 5 & 1 & 1 & 3 & 5 & 5 & 1 & No & $200 \mathrm{~m}$ & $>4 \mathrm{MPa}$ & $>5 \times 10^{-4}$ \\
\hline
\end{tabular}


Table 2

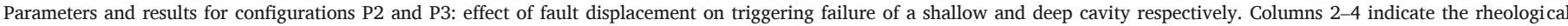

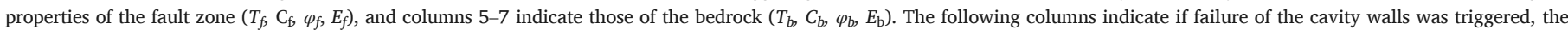

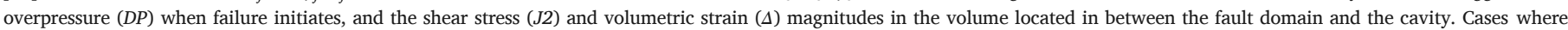
failure of the fault does not occur, display values for the indicated applied DP. (*) Run P2-A was tested for a 200 MPa range of applied over pressure.

\begin{tabular}{|c|c|c|c|c|c|c|c|c|c|c|c|c|c|}
\hline & Config & $\begin{array}{l}T_{f} \\
(\mathrm{MPa})\end{array}$ & $\begin{array}{l}\mathrm{C}_{\mathrm{f}} \\
(\mathrm{MPa})\end{array}$ & $\varphi_{f}$ & $\begin{array}{l}E_{f} \\
(\mathrm{GPa})\end{array}$ & $\begin{array}{l}T_{b} \\
(\mathrm{MPa})\end{array}$ & $\begin{array}{l}C_{b} \\
(\mathrm{MPa})\end{array}$ & $\varphi_{b}$ & $\begin{array}{l}E_{b} \\
(\mathrm{GPa})\end{array}$ & $\begin{array}{l}\text { Fault } \\
\text { Failure? }\end{array}$ & $\begin{array}{l}D P \\
(\mathrm{MPa}) \text { at } \\
\text { failure }\end{array}$ & $\begin{array}{l}\text { Shear } \\
\text { Stress } \\
\text { (MPa) }\end{array}$ & $\begin{array}{l}\text { Volumetric } \\
\text { strain }\end{array}$ \\
\hline \multirow[t]{9}{*}{ Shallow Cavity } & P2_1 & 1 & 2 & 0 & 40 & 2 & 5 & 15 & 40 & No & $90 \mathrm{MPa}$ & $>3 \mathrm{MPa}$ & $>2 \times 10^{-5}$ \\
\hline & P2-A & 1 & 2 & 1 & 25 & 3 & 5 & 15 & 25 & Yes & $\begin{array}{l}150 \mathrm{MPa} \\
*\end{array}$ & $>6 \mathrm{MPa}$ & $>2 \times 10^{-5}$ \\
\hline & P2_2 & 1 & 2 & 0 & 10 & 3 & 5 & 15 & 10 & No & $90 \mathrm{MPa}$ & $>5 \mathrm{MPa}$ & $>3 \times 10^{-5}$ \\
\hline & P2_3 & 1 & 2 & 0 & 1 & 3 & 5 & 15 & 1 & Yes & $80 \mathrm{MPa}$ & $>5 \mathrm{MPa}$ & $>5 \times 10^{-4}$ \\
\hline & P2-B & 1 & 2 & 0 & 40 & 3 & 5 & 10 & 40 & Yes & $75 \mathrm{MPa}$ & $>4 \mathrm{MPa}$ & $>1 \times 10^{-5}$ \\
\hline & P2_4 & 1 & 2 & 0 & 40 & 3 & 5 & 5 & 40 & Yes & $57.5 \mathrm{MPa}$ & $>5 \mathrm{MPa}$ & $>1 \times 10^{-5}$ \\
\hline & P2_5 & 1 & 2 & 0 & 1 & 2 & 5 & 15 & 10 & No & $50.0 \mathrm{MPa}$ & $>2 \mathrm{MPa}$ & $>4 \times 10^{-5}$ \\
\hline & P2_6 & 1 & 2 & 0 & 10 & 3 & 5 & 2 & 20 & Yes & $40.0 \mathrm{MPa}$ & $>8 \mathrm{MPa}$ & $>2 \times 10^{-5}$ \\
\hline & P2_7 & 1 & 2 & 0 & 10 & 3 & 5 & 5 & 20 & Yes & $57.5 \mathrm{MPa}$ & $>5 \mathrm{MPa}$ & $>3 \times 10^{-5}$ \\
\hline \multirow[t]{5}{*}{ Deep Cavity } & P3_1 & 1 & 2 & 0 & 40 & 2 & 5 & 15 & 40 & Yes & $7.5 \mathrm{MPa}$ & $>5 \mathrm{MPa}$ & $>5 \times 10^{-6}$ \\
\hline & P3_2 & 1 & 2 & 0 & 40 & 2 & 5 & 5 & 40 & Yes & $7.5 \mathrm{MPa}$ & $>5 \mathrm{MPa}$ & $>5 \times 10^{-6}$ \\
\hline & P3_3 & 2 & 5 & 1 & 1 & 3 & 5 & 15 & 1 & Yes & $30.0 \mathrm{MPa}$ & $>20 \mathrm{MPa}$ & $>1 \times 10^{-3}$ \\
\hline & P3_4 & 1 & 2 & 0 & 10 & 2 & 5 & 5 & 20 & Yes & $12 \mathrm{MPa}$ & $>10 \mathrm{MPa}$ & $>2 \times 10^{-5}$ \\
\hline & P3_5 & 1 & 2 & 1 & 10 & 2 & 5 & 5 & 20 & Yes & $35 \mathrm{MPa}$ & $>10 \mathrm{MPa}$ & $>2 \times 10^{-5}$ \\
\hline
\end{tabular}

duces deviatoric and volumetric strain in the surrounding bedrock, with asymmetric dilatational and constrictive lobes on either east and western sides of its northern and southern extremities. Consequently the intervening domain in between the northern tip of the fault zone and the magmatic cavity undergoes dilatational strain $(\Delta>0)$ (Fig. 3).

\subsubsection{Fault motion occurring near a shallow cavity at $6 \mathrm{~km}$ depth (P1 cases)}

Firstly, we test the influence of the bedrock's Young's Modulus. When simulating an homogeneous crust $\left(\mathrm{E}_{\mathrm{b}}=\mathrm{E}_{\mathrm{f}}=40 \mathrm{GPa}\right)$ and a moderate bedrock friction angle of $\varphi_{\mathrm{b}}=15^{\circ}$ (P1-1, Fig. 4a), the cavity walls yield plastically from DD $=160 \mathrm{~m}$. At the onset of failure, shear stress $\left(\mathrm{J}_{2}(\sigma)\right)$ surrounding the cavity's western edge is $>40 \mathrm{MPa}$, and diffuse volumetric strain $\left(\mathrm{I}_{1}(\varepsilon)\right) \Delta>1 \times 10-4$. Moreover, the plastic domain encompasses the fault zone and an area of $\sim 5 \times 15 \mathrm{~km} 2$ at the surface. Reducing the bedrock's Young's modulus increases the critical fault displacement required to fail the cavity walls. When $\mathrm{E}_{\mathrm{b}}$ is reduced to $10 \mathrm{GPa}$ and 1 GPa (P1-2 and P1-3, Fig. 4b), cavity wall failure does not occur, at least in the range of applied displacements $<200 \mathrm{~m}$. However, it does promote an increase in the diffuse volumetric strain throughout the bedrock to $\Delta>5 \times 10_{-4}$.
We also test the bedrock's friction angle $\left(\varphi_{\mathrm{b}}\right)$. When the bedrock friction angle is set lower $\left(\varphi_{\mathrm{b}}=5^{\circ}\right.$ and $1^{\circ}$ in cases P1-4 and P1-6) at a given $E_{b}=E_{f}$, cavity wall failure is triggered at lower amounts of fault displacement. For example, considering models P1-1, P1-4 and P1-6 $\left(\varphi_{\mathrm{b}}=15^{\circ}, 5^{\circ}\right.$ and $1^{\circ}$ respectively), cavity wall failure occurs for $160 \mathrm{~m}$, $100 \mathrm{~m}$, and $60 \mathrm{~m}$ respectively. In the latter scenario (P1-6, Fig. 4d), the shear stress and dilatational strain in the intermediate bedrock space are in the order of $12 \mathrm{MPa}$ and $\Delta \sim 2 \times 10^{-5}$ respectively. Therefore, a more resistant bedrock (i.e. thus higher values of $\varphi_{b}$ ) requires greater amounts of fault slip to load up to its yield and fail at the cavity walls.

When the Young's modulus is reduced to extreme values of $\mathrm{E}_{\mathrm{b}}=\mathrm{E}_{\mathrm{f}}=1 \mathrm{GPa}$, cavity wall failure never occurs, instead it only allows failure of the bedrock above and locally around the fault. This is understandable as the shear stress in this domain cannot exceed $J_{2} \sim 8 \mathrm{MPa}$ (P1-5, Fig. 4c), as the bedrock cannot accumulate enough stress and instead withstands more deformation. Nonetheless, as mentioned above, an order of magnitude reduction in the bedrock's Young's modulus allows for 10-50 times greater than before diffuse volumetric strain in the intermediate bedrock.

We also evaluate a heterogeneous medium with a contrast in Young's modulus between the bedrock and the fault zone, where $E_{b}>E_{f}$. The most favorable case for cavity wall failure occurs when
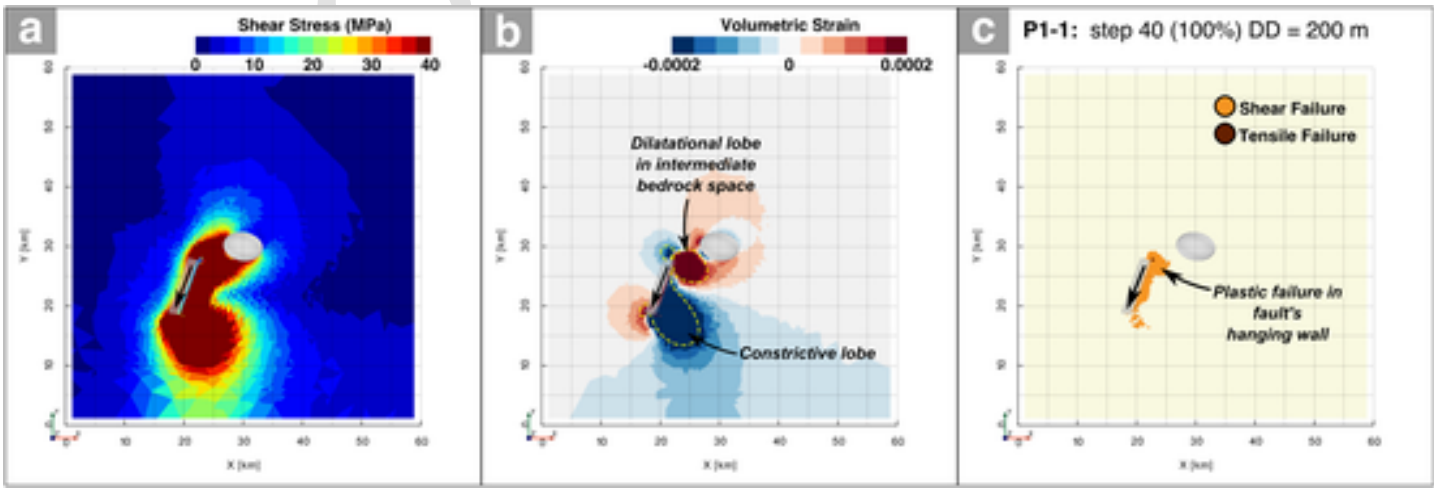

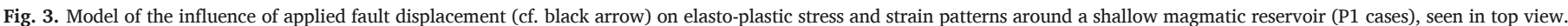

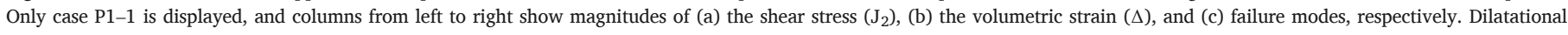
lobes are generated at the north-east and south-west of the fault when applying a dextral displacement, whereas plastic failure is concentrated in the fault's hanging wall. 

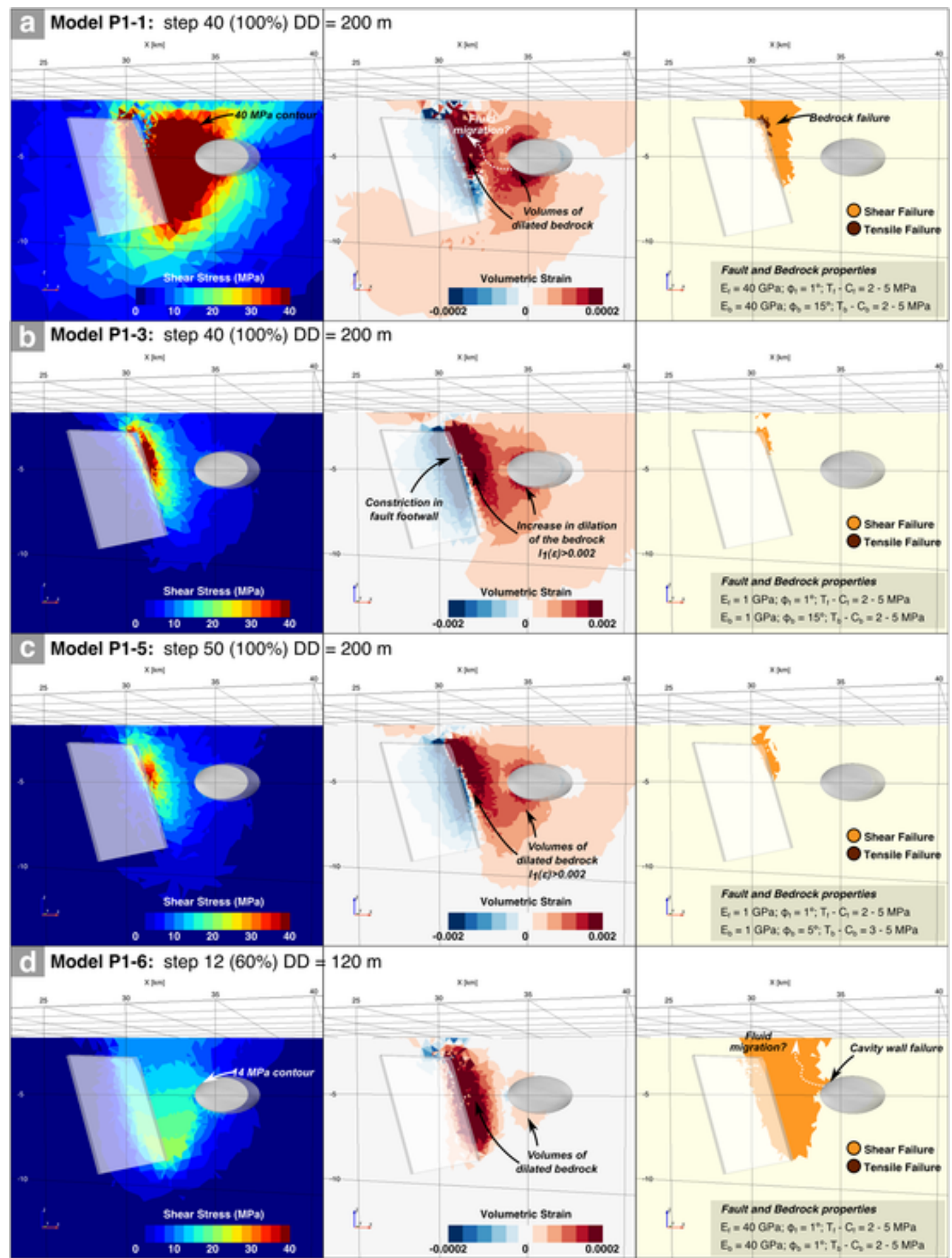

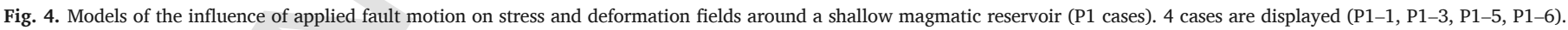

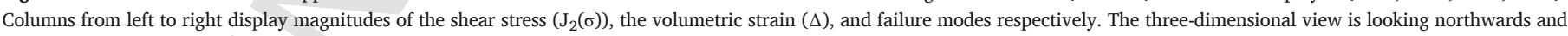

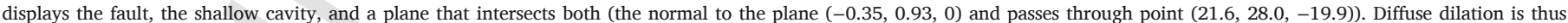

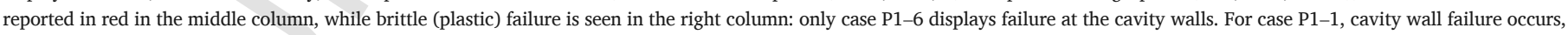

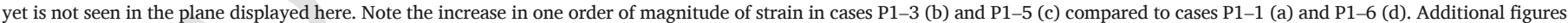
are provided in Appendix B.

this contrast is moderate, as in case P1-8 where $E_{f}=10 \mathrm{GPa}$, $E_{b}=20 \mathrm{GPa}$ and fault-bedrock frictional strength is $T-C-=2-5 \mathrm{MPa}$, $\varphi=1^{\circ}$. Here, cavity failure occurs for $D D=120 \mathrm{~m}$. If the Young's modulus contrast is too high (as in P1-10), the fault zone "absorbs" the imposed shearing, and the shear stress in the bedrock between fault and cavity does not exceed $\mathrm{J} 2 \sim 5 \mathrm{MPa}$.

We can generalize the conditions required for cavity failure when a fault displacement is applied nearby a magmatic cavity: 
- The highest the Young's modulus of the bedrock, the easiest it is to propagate stress from the fault zone and induce cavity wall failure for only several tens of meters of fault displacement. Reciprocally, the lower the bedrock's Young's modulus, the greater the amount of fault displacement $(D D>100 \mathrm{~m}$ ) required to transmit sufficient stress to a magmatic reservoir and have it fail.

- The effective Young's modulus of the fault zone itself must be high enough compared to the surrounding bedrock, otherwise it absorbs most of the stress induced by the applied fault displacement. Note that the fault's frictional strength cannot influence the resulting pattern of deformation since the application of shear motion along this fault zone impedes it to react mechanically on its own.

- Increasing the bedrock's frictional strength delays the onset of cavity failure with increasing applied fault zone motion. Hence, the domain of induced plastic deformation expands further away around the fault zone.

\subsubsection{Effect of applied fault displacement on a deep cavity at $10 \mathrm{~km}$ depth (P4 cases)}

We now consider the effect of fault displacement on a deep magma cavity. Our main result is that no combination of the rheological properties led to bedrock failure at the cavity walls. As illustrated in Fig. 5a (left panel), high bedrock Young's modulus such as in P4-1 allows for slightly greater stress propagation away from the slipping fault zone than in a more compliant bedrock (P4-2; Fig. 5b): $\mathrm{J}_{2}$ intensities reach $\sim 20$ MPa near the cavity walls after $185 \mathrm{~m}$ of fault displacement. In all the scenarios tested the intermediate space and the domain above the cavity experience diffuse dilatational strain $\Delta>10^{-5}$, for fault displacements from $D D=100 \mathrm{~m}$ onwards (and increasing with increasing displacements). This diffuse (and elastic) dilation is inversely proportional to the bedrock's Young's modulus, so that $\Delta>10^{-4}$ when $E_{b}$ is set ten times smaller (1 GPa, P4-2, Fig. 5b).

\subsection{Configuration 2: over-pressurized reservoirs}

Now, an overpressure $(D P)$ is applied stepwise along the walls of either a shallow or a deep oblate cavity (cavity centers are set at $6 \mathrm{~km}$ or $15 \mathrm{~km}$ depth), simulating a pressurized magmatic reservoir. In both geometries, the cavity pushes the adjacent bedrock domain outwards, inducing greater dilatation at the elongated edges of the ellipsoidal cavity axes (Fig. 6), as shown for instance by Gerbault et al. (2018). In expanding radially away through the bedrock space, shear stresses $\left(J_{2}(\sigma)\right.$ ) first affect the closest northern tip of the distant fault zone then decay southward, inducing both dilatation and possibly a dextral strike-slip relative motion, with the easternmost wall of the fault zone undergoing greater southward motion than its western wall (Fig. 6). In this configuration, as in the former one, we refer to 'fault failure' when plastic yield occurs inside the fault zone domain.

\subsubsection{Effect of a shallow cavity on a crustal fault zone (P2 cases)}

We first test the influence of the bedrock's Young's modulus. With equal bedrock and fault zone Young's modulus $\left(\mathrm{E}_{\mathrm{b}}=\mathrm{E}_{\mathrm{f}}=40 \mathrm{GPa}\right)$ (P2-1, Fig. 7a), and a standard bedrock friction angle of $\varphi_{b}=15^{\circ}$ $\left(\mathrm{T}_{\mathrm{b}}-\mathrm{C}_{\mathrm{b}}=5-10 \mathrm{MPa}\right)$, the fault does not yield plastically for the overpressure limit tested $(100 \mathrm{MPa})$. At DP $=90 \mathrm{MPa}$, the cavity walls fail, and the plastic domain around the cavity expands, up to the surface.

Diminishing the bedrock's Young's modulus does not significantly affect the stress field pattern around the inflating magma cavity, since its distribution depends on the plastic threshold and not directly on its elastic properties. When testing $\mathrm{E}_{\mathrm{b}}=\mathrm{E}_{\mathrm{f}}=10 \mathrm{GPa}$ (P2-2), the fault still cannot yield plastically in the range of tested overpressure. Dimin-

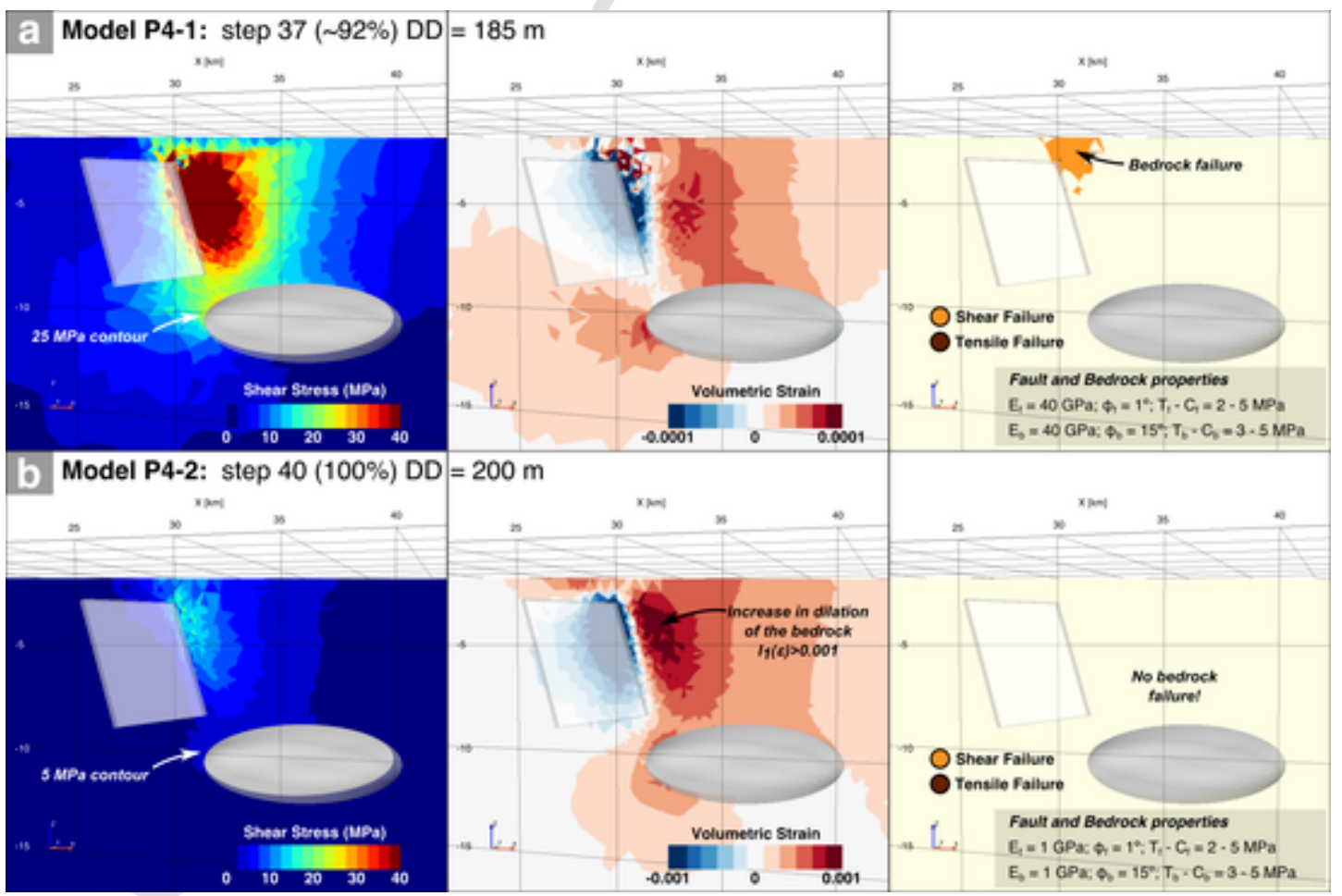

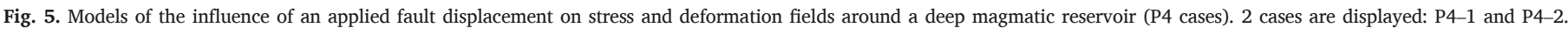

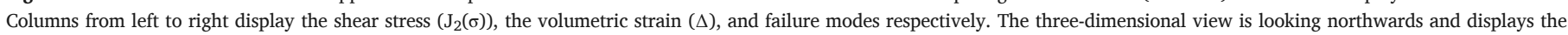

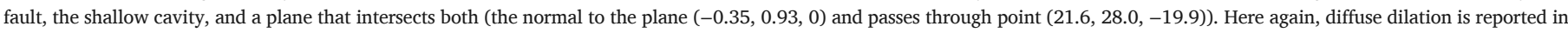

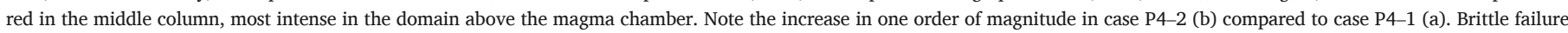

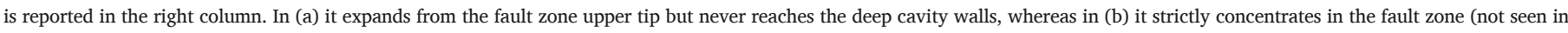
the shown plane). See Appendix B for additional figures. 

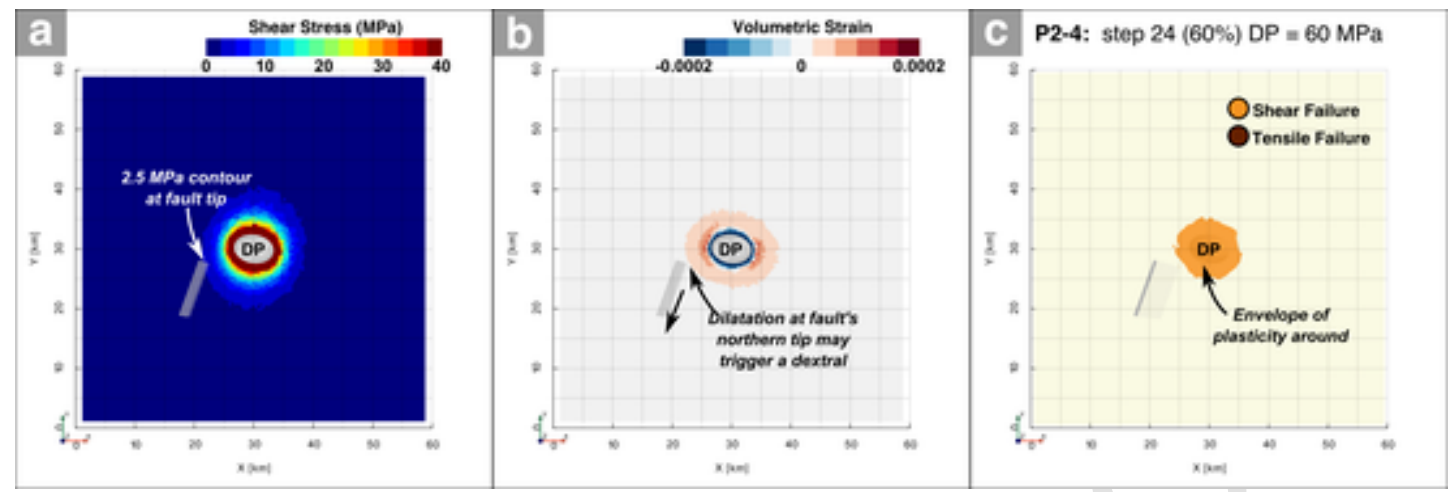

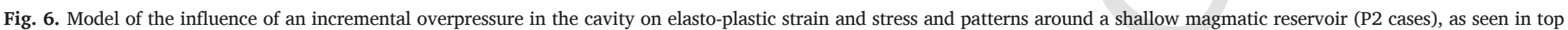
view. Only case P2-4 is displayed, and columns from left to right show magnitudes of (a) the shear stress $\left(J_{2}(\sigma)\right.$ ), (b) the volumetric strain $(\Delta)$, and $(c)$ failure modes respectively.

ishing it by an order of magnitude $\left(\mathrm{E}_{\mathrm{b}}=\mathrm{E}_{\mathrm{f}}=1 \mathrm{GPa}\right.$, P2-3), allows fault failure to occur at a critical overpressure of $D P=72 \mathrm{MPa}$. However, an order of magnitude reduction in $\mathrm{E}_{\mathrm{b}}$ affects the surrounding volumetric strain proportionally, leading to a greater diffuse volumetric dilation around the magma cavity. (Fig. 7b).

Secondly, we test the bedrock's strength $\left(\varphi_{b}, T_{b}, C_{b}\right)$. Increasing magmatic overpressure in an elasto-plastic bedrock leads to the expansion of the three-dimensional envelope of plasticity (a sphere in the case of a spherical magma cavity in an infinite medium), within which the stress field remains at its maximum yield value; the equivalent radius of this plastic envelope not only depends on the inverse of the bedrock's yield strength, but also expands logarithmically with the applied overpressure (Timoshenko and Goodier, 1970; Gerbault et al., 2018, recall it in their eq. 4). Hence, when the bedrock friction is set lower, the relatively low magnitude of shear stress actually spreads further away to reach the fault zone, enabling its plastic failure. Model P2-4 illustrates this effect with a bedrock friction set to $5^{\circ}$ instead of $15^{\circ}$ (Fig. $7 \mathrm{c}$ ): the fault fails plastically for an overpressure of only $D P=55 \mathrm{MPa}$. Moreover, considering the cubic decay of the imposed stress field with radial distance from the pressurized reservoir, and the critical distance between the fault and cavity $(\sim 4 \mathrm{~km})$, we note that the only way to reproduce plastic failure of the fault is to set a very low fault zone frictional strength. The models shown in this section show that fault friction has to be as low as $0-1^{\circ}$ for fault failure to occur. Alternatively, either the reservoir radius must be larger, DP must be greater, or the fault must be much closer (cf. Appendix D for complementary models with a fault zone set much closer).

Another way to facilitate fault zone failure might also be to reduce its Young's modulus with respect to that of the bedrock, all the more that field measurements point to such properties (Stanton-Yonge et al., 2020, see discussion). We have tested several combinations of the bedrock and fault zone stiffness contrasts. Stiffness contrasts in between the bedrock and the fault zone actually lead to the more compliant fault zone domain deforming internally as it is being squeezed by the external stiffer bedrock domain (P2-5). Actually, some high contrast cases led to the technical collapse of the fault zone mesh onto itself. The most favorable values for fault zone failure were found for the model case P2-6, where $E_{b}=20 \mathrm{GPa}$ and $E_{\mathrm{f}}=10 \mathrm{GPa}$. In that case the bedrock's friction was set as low as $2^{\circ}$, and fault zone failure was achieved for an overpressure $D P \sim 38 \mathrm{MPa}$. All other configurations required overpressures greater than $50 \mathrm{MPa}$ for fault zone plastic failure to occur. In model case P2-6, the shear stress in the intermediate space reaches $\mathrm{J}_{2} \sim 10 \mathrm{MPa}$ and dilatational strain reaches $\Delta \sim 5 \times 10^{-5}$ (Fig. 7d). Fault failure initiates from the top downwards and is immediately followed by general failure if $D P$ continues to increase, because of the small strength contrast existing between fault and bedrock domains.
A final series of tests show that fault failure barely occurs when its friction angle is set above $\varphi_{\mathrm{f}} \geq 1^{\circ}$, at least in the range of the applied overpressures DP $\leq 100 \mathrm{MPa}$. This result (not shown here because there is no failure) is consistent with expectations. Considering that the contribution of $1^{\circ}$ in friction angle on the fault zone's yield strength is proportional to $\tan (\varphi) \cdot \rho g z$ (neglecting the none-lithostatic component on the normal stress), and that the closest distance of the fault zone to the inflating cavity is $4 \mathrm{~km}$ (at $\mathrm{z}=5 \mathrm{~km}$ depth), the contribution to the yield strength amounts $\sim 2.5 \mathrm{MPa}$. For this amount of shear stress to be reached at the fault zone requires that 10 times more overpressure must be applied from the pressure source, hence DP should increase by another $\sim 25 \mathrm{MPa}$. This value added to the DP $>38 \mathrm{MPa}$ reaches $\sim 60 \mathrm{MPa}$, a quite large value given estimates of standard magmatic overpressures related to volcanic inflation worldwide.

From these observations we can generalize the conditions for fault displacement triggered by an overpressure in a nearby shallow elliptical reservoir:

- Young's modulus contrasts between the bedrock and the fault zone should remain moderate in order for fault zone brittle failure to occur. The most favorable values for fault failure triggering are $E_{b-f}=10-20 \mathrm{GPa}$. High contrasts in $E$ in turn, lead to compaction of the fault zone domain, while low bedrock Young's modulus requires a larger amount of overpressure for fault motion to occur.

- Fault failure never occurs when the friction angle of the fault zone is above $\varphi \mathrm{f} \geq 1^{\circ}$, at least in the range of tested DP $\leq 100 \mathrm{MPa}$ and a Young's modulus as high as $40 \mathrm{GPa}$. Moreover, high bedrock friction $\left(\varphi_{\mathrm{b}}>10^{\circ}\right)$ delays fault failure; in comparison low bedrock frictional strength circumscribes the stress field, which then accommodates increasing reservoir overpressure by spreading over greater distances. Moreover, a small difference in brittle strength between fault and bedrock leads to fault failure just prior to general bedrock failure with overpressure increase.

\subsubsection{Effect of a deep cavity on a crustal fault zone (P3 cases)}

Fault failure triggered by an inflating deep cavity is found easier and less restrictive for the combinations of rheological parameters tested here. Failure occurs with reservoir overpressures $(D P)$ as low as $8 \mathrm{MPa}$ (and in general up to $D P \sim 30 \mathrm{MPa}$ ). This is due to the fact that in this configuration, the applied overpressure affects a broader domain due to larger cavity dimensions (in comparison to the shallow cavity), and the distance between fault and cavity is reduced to about $3 \mathrm{~km}$.

For a model case with similar elastic and frictional strength properties as in the shallow cavity configuration, now fault failure is triggered as soon as $D P=8 \mathrm{MPa}$ (P3-1, Fig. 8a). This most favorable condition is achieved when both the bedrock and fault zone domain are assigned high Young's modulus $\left(\mathrm{E}_{\mathrm{b}}=\mathrm{E}_{\mathrm{f}}=40 \mathrm{GPa}\right)$, and the fault zone has a 


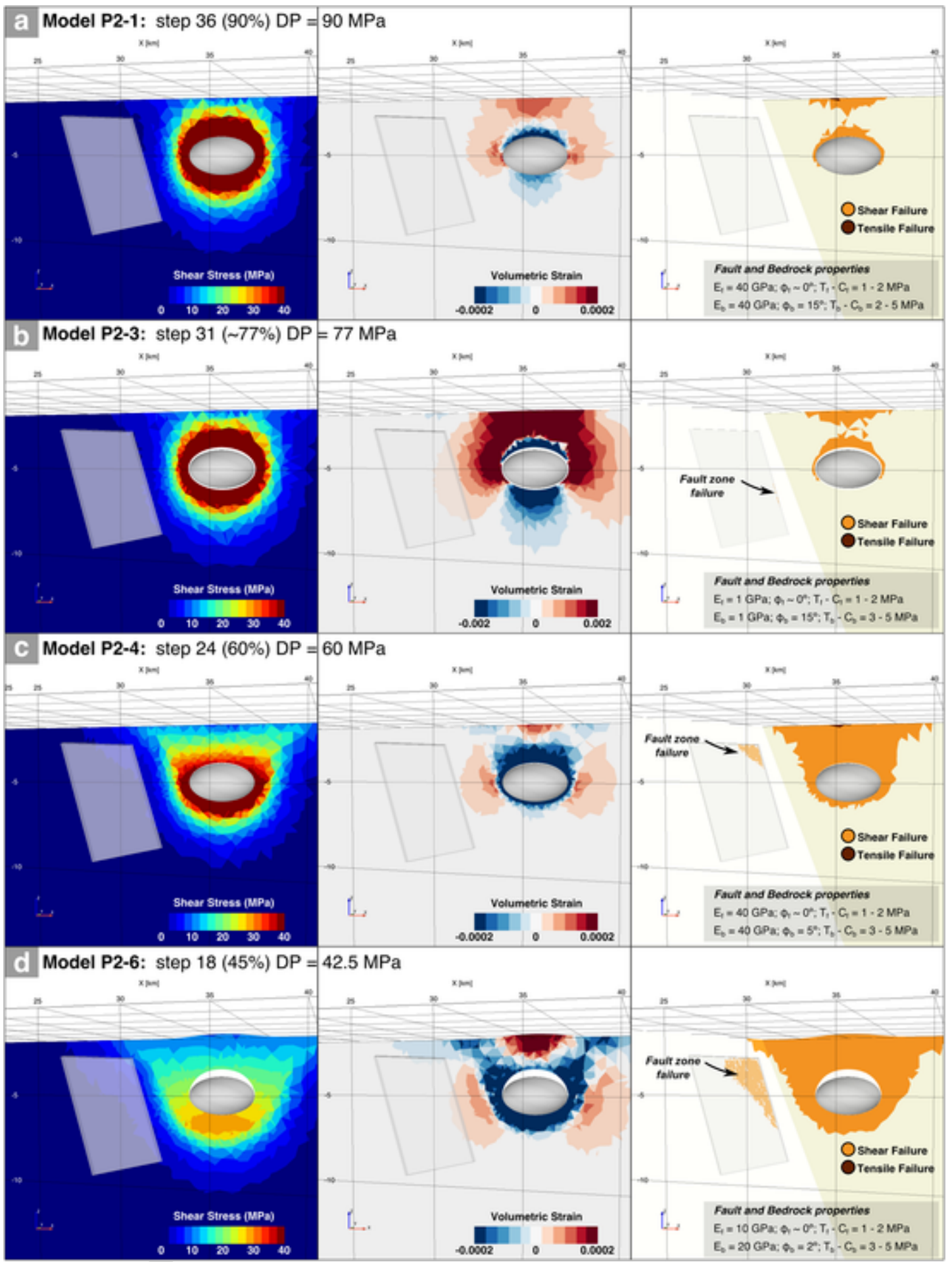

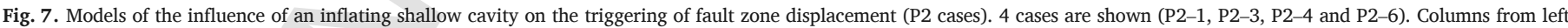

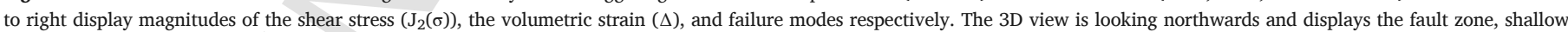

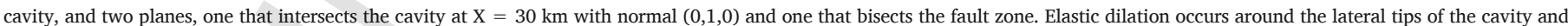

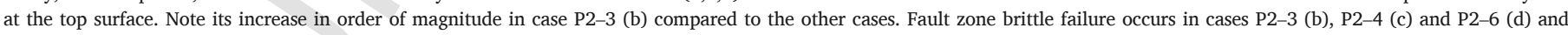
propagates from the northern tip south and downwards.

minimal frictional strength $\left(\varphi_{\mathrm{f}}=0^{\circ}\right)$. At the onset of fault failure, dilatational strain in the intermediate bedrock is in the order of $\Delta \sim 5 \times 10^{-6}$, while shear stress reaches $J_{2} \sim 5 \mathrm{MPa}$. Fault failure is followed by cavity failure when $D P=32.5 \mathrm{MPa}$ and surface failure when $D P=37.5 \mathrm{MPa}$. Because the deviatoric state of stress state in the bedrock domain can remain as low and behaves elastic, bedrock fric- tional strength does not have a significant impact; in fact the critical overpressure for fault zone failure remains the same whether $\varphi_{\mathrm{b}}=15^{\circ}$ or $\varphi_{\mathrm{b}}=5^{\circ}$ (cases P3_1 and P3_2, respectively). Conversely, when considering a high friction bedrock $\left(\varphi_{\mathrm{b}}=15^{\circ}\right)$ and an overall compliant medium $\left(\mathrm{E}_{\mathrm{b}}=\mathrm{E}_{\mathrm{f}}=1 \mathrm{GPa}\right)$ as in case P3_3 (Fig. 8b), fault failure initiates for a cavity overpressure DP $\sim 30 \mathrm{MPa}$, but here dilatational strain 


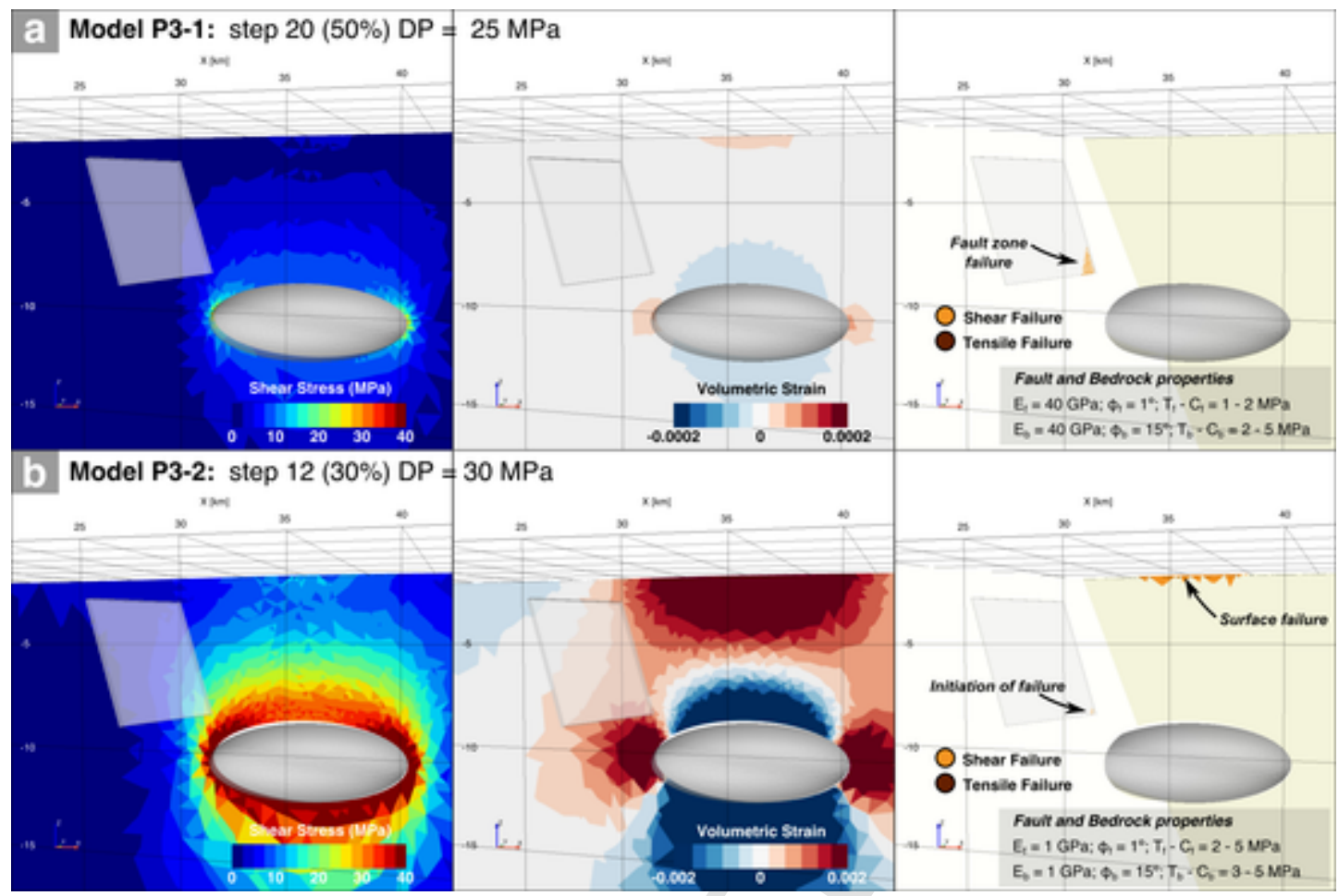

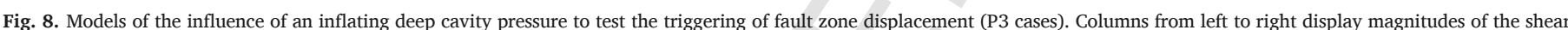

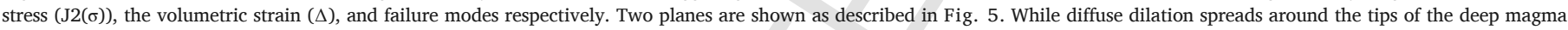

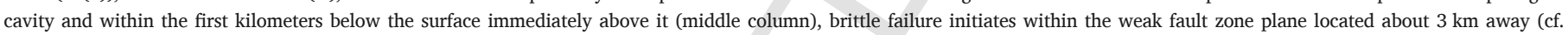
Appendix B for additional figures).

in the intermediate space and around the cavity is much greater $\left(\Delta \sim 5 \times 10^{-3}\right)$.

Different combinations of bedrock and fault zone elastic and frictional strength properties show that in general, the critical magma overpressure that enables fault zone plastic failure stands around $D P \sim 10 \mathrm{MPa}$ when effective fault friction is $\varphi_{\mathrm{f}}=0^{\circ}$ (for instance P3_4). We could thus increase the effective friction of the fault zone to $\varphi_{\mathrm{f}}=1^{\circ}$ and still maintain a critical magma overpressure $D P$ below $35 \mathrm{MPa}$ (cases P3_3 and P3_5).

\section{Dilatation and slip tendency extracted from modelled stress fields: application to TSPVC}

We use the slip and dilation tendency technique to scan the domains where diffuse and plastic strain occur. Here we indicate the orientations where slip and/or dilation are promoted for a given stress state on any possible planar surface. Slip is likely to occur when the ratio of shear stress to normal stress ( $T_{s}=\frac{\sigma_{s}}{\sigma_{n}}$; Slip Tendency) acting on a planar surface equals or exceeds the frictional resistance to sliding of the planar surface in question (Ferrill et al., 1999). Dilation tendency ( $\left.T_{d}=\frac{\left(\sigma_{1}-\sigma_{n}\right)}{\left(\sigma_{1}-\sigma_{3}\right)}\right)$ in turn depends on the normal stress and is thus evaluated by normalizing the normal stress with the differential stress (Ferrill et al., 1999). Those planar surfaces well oriented for either slip or dilation should be more transmissive to fluid flow and could be related to locations of mineralization, pathways for magma injection or storage. In addition, Moeck et al. (2009) showed that the slip and dilation tendency technique can be used as a proxy for reactivation of faults due to fluid flow in a geothermal setting, such as that observed in the TSPVC. Below, we present the algorithmic methodology that was undertaken, and then display examples taken from our models. We then contrast and compare the resulting slip and dilation tendencies with geological structures observed in the TSPVC.
5.1. Algorithmic procedure to extract stress and strain orientations from the Adeli models

Appendix E Fig. E1 presents a flow chart describing the algorithmic procedure to obtain slip and dilation tendency from the Adeli modelling results presented in Section 4 (the python script developed for the analysis and an example .vtk file can be found in the supplementary material). We selected models from configurations P1 and P2 to examine the slip and dilation tendency for 2 spherical domains of radius $1 \mathrm{~km}$ located in the intermediate space, and slightly to the NE of the cavity (inset box in Appendix E Fig. E2 for location reference).

\subsection{Example cases from modelling results $P 1$ and $P 2$}

Fig. 9a displays this analysis for the test case P1-1 after cavity failure occurred. In the intermediate space, $\sigma_{1}$ plunges steeply, whereas $\sigma_{2}$ and $\sigma_{3}$ tend to remain horizontal - subhorizontal. This is consistent with horizontal stretching exerted from the south-west by the applied fault motion. At shallower depths, slip tendency increases due to a reduction in frictional strength due to less gravity. To the NE of the cavity, where the MGS anomaly lies, and above the cavity, we note that slip tendency decreases (Appendix D), because these locations are further away from the traction source. Moreover, dilation tendency domains $(>0.9)$ are subvertical to vertical at all depths and strike between NS and $\mathrm{N}^{\circ} 0^{\circ} \mathrm{W}$ (dipping to east), with rotations between these orientations occurring between the tested depths (Fig. 9b and Appendix E Fig. E2). The same pattern is still observed $\sim 10 \mathrm{~km}$ to the NE.

We also display slip and dilation tendencies for the modelled stress state in case P2-4, after fault failure occurred (Fig. 9c). We evaluate a spherical domain to the NE of the cavity (close to the MGS). High slip tendency $(\sim 0.2-0.3)$ occurs at shallow depths with a quadri modal concentration in each quadrant. This pattern is similar to that observed 


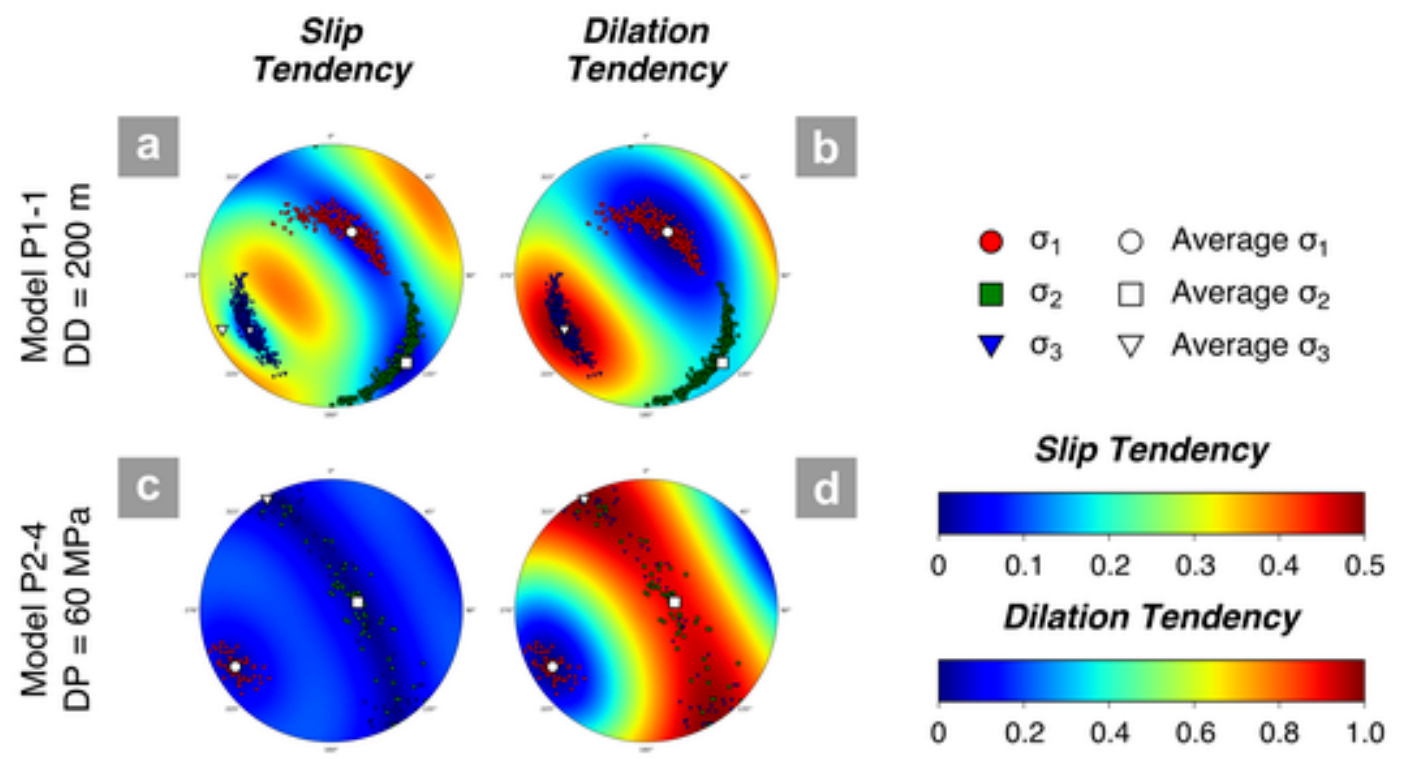

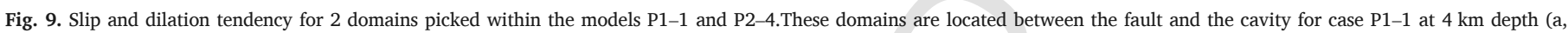

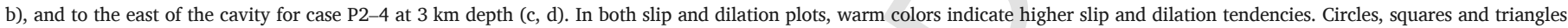
indicate the orientation of $\sigma_{1}, \sigma_{2}$ and $\sigma_{3}$ respectively.

in the intermediate bedrock due to the radial geometry of the loading condition. Very high dilation tendency domains $(\sim 1)$ are shallow dipping (sub-horizontal to horizontal levels) at depths 8,6 and $4.8 \mathrm{~km}$, and as we approach the surface (1.8 $\mathrm{km}$ depth), they become vertical, with dilation planes $\sim \mathrm{N} 60^{\circ} \mathrm{E} / 80-90^{\circ}$ (Fig. $9 \mathrm{~d}$ and Appendix E Fig. E2).

\subsection{Comparison with the case study}

The results obtained from the slip-dilation tendency analysis for the chosen models are to some extent, compatible with geological structures observed in the TSPVC (Sielfeld et al., 2019b). For example:

- The subhorizontal NE-trending $\sigma_{3}$ and dilation occurring in the intermediate space, is consistent with the formation and reactivation of NE-ENE striking dextral normal faults that predominate in the Tatara Damage Zone (TDZ Fig. 1b). Thus, these observed preexisting fault zones might reactivate as a result of dextral displacement of the Melado fault zone over a given threshold. But they could also reactivate due to the inflation of a magmatic reservoir underneath. Moreover, these NE-striking oblique slip structures could form as wing cracks in the tensional end of the Melado fault, and are not fully explained by the bulk regional stress. Consequently, they may well be the result of dextral motion along the Melado fault zone.

- The ENE trending dike intrusions observed on the field cannot be explained by either the P1 or P2 model configurations. The numerical models in configuration $\mathrm{P} 1$ predict NW oriented high dilation tendency that could result in NW-striking dikes forming, and only in configuration P2-1 at a depth of $1.8 \mathrm{~km}$, high dilation tendency occurs in NE-striking subvertical domains that could induce diking in that orientation. We then speculate that these features instead respond to the far field regional transpressional state of stress induced by oblique plate convergence.

- The radial pattern observed above the inflating cavity might explain opening pore space in all directions, that best eases the percolation of geofluids, consistent with the formation of the Mariposa geothermal system in a similar location above the observed C2 conductive anomaly identified in the upper-middle crust.

\section{Discussion}

Here we studied the mechanical interaction between a strike-slip fault zone and a magma reservoir with three-dimensional elasto-plastic numerical experiments. Below we further discuss some points that arise with our results, particularly the representativeness of the chosen rheological parameters such as Young's modulus and friction angle, the significance of the identified dilatational domains, feedback processes between fluid flow and deformation as observed from our models and the implications for geothermal reservoirs.

\subsection{Synthesis of model mechanical results}

The models presented above show two key mechanical responses that arise from both loading configurations: (1) either a localized shear failure near the magmatic reservoir or the fault zone, or (2) a diffuse dilation expanding within the intermediate domain located in between, over several kilometers wide. These mechanical responses denote the interaction between a weak fault zone and a geofluid reservoir at a kilometric scale. We postulate that the diffuse dilation is a proxy to the opening of pore space and/or volumetric micro cracking (Simpson et al., 2001; Guéguen and Schubnel, 2003; Lamur et al., 2017) that potentially allows for hydrothermal or magmatic fluids to percolate and infiltrate towards the surface, or be stored, potentially advecting heat and mineral elements of economic interest. The occurrence and magnitude of this response, and the occurrence or not of failure of the cavity or fault (here taken as when plastic yield is reached) depends on the effective elastic properties and frictional strength of the bedrock and the fault zone.

Regarding the mechanical interaction between a crustal cavity and a fault zone, firstly, the Young's modulus is required to be sufficiently high ( $\mathrm{E} \geq 20 \mathrm{GPa}$ ), for localized shear failure to occur (given a range of frictional and tensile strength values). In those cases, volumetric strain is in the order of $10^{-5}-10^{-4}$ in the intermediate space and the shear stress $>10 \mathrm{MPa}$ (Tables 1 and 2). In configuration 1, a stiffer bedrock allows for more shear stress to accumulate (up to $\sim 90 \mathrm{MPa}$ in case P1- 
1 ), while in configuration 2 , the range of shear stress is more reduced (Fig. 10 b, e). Conversely, compliant bedrock and fault domains $(\mathrm{E} \simeq 1 \mathrm{GPa})$ allow for high diffuse and distributed strain in the order of $10^{-3}$ over a bulk volume $\sim 5 \times 5 \times 5 \mathrm{~km}^{3}$, which could be significant for fluid flow and permeability increase (Fig. $10 \mathrm{c}$, f). Additionally, the friction angle of the bedrock plays a key role in delaying failure, with high friction angle allowing for failure to occur after $>100 \mathrm{~m}$ of applied displacement (configuration 1) or $>100 \mathrm{MPa}$ of applied overpressure (configuration 2) (Fig. 10 a, d).

Here, the fault displacement most likely considers the effect of cumulated and repeated fault motion over several seismic cycles of intra-arc fault zones (through earthquake rupture) and the potential occurrence of creep flow within the fault domain, rather than single "independent" events set out of their tectonic loading context. Coupled seismic and aseismic slip has been reported in both natural faults and in experiments, and account for the total crustal deformation that accommodates tectonic stresses (e.g. Cowie and Scholz, 1992; Rowe and Griffith, 2015). Such localized slip processes are associated with permeability enhancement, fluid flow, and mineralization (Micklethwaite and Cox, 2006), and although they are not directly represented by our models here, the link is rather straightforward.

Additionally, the progressive pressure increase modelled here could relate to inflation processes over several years in a magmatic reservoir. The modelled critical overpressures for a deep cavity stand in the range of common evaluations worldwide, and should be easily recovered when inverting geodetic data over specific areas, as for example from point source models and the temporal behavior of surface displacements (e.g. Novoa et al., 2019). On the contrary, the higher values of critical overpressure obtained for a shallow cavity appear inappropriate given common estimates from geodetic data or petrology (e.g. Jellinek and DePaolo, 2003; Currenti and Williams, 2014; Grosfils et al., 2015). Therefore, we conclude that a relatively shallow ( $\sim 5 \mathrm{~km}$ depth) magma cavity can only influence a nearby fault zone if it is located significantly closer to the $4 \mathrm{~km}$ distance that was chosen here. For example, if we consider a bedrock of $E_{b}=10 \mathrm{GPa}, 10 \mathrm{~m}$ of slip on $\mathrm{a} \sim 10 \mathrm{~km}$ long fault zone will produce a macroscopic shear strain and stress of the order of $10^{-3}$ and $10 \mathrm{MPa}$ in the surrounding bedrock (based on Hooke's law). The decay of that shear stress with distance can be approximated at first order as linear (Dieterich and Smith, 2009 ), so that at $4 \mathrm{~km}$ away from the fault, it will be $<4 \mathrm{MPa}$. A "sphere of influence" smaller than 1 to $2 \mathrm{~km}$ appears a good rule of thumb given how the stress field decays away from inflating sources. As an illustration, Appendix D displays an extra P1 model case with a fault zone set only $800 \mathrm{~m}$ away from the magma cavity's walls; an applied overpressure of $52 \mathrm{MPa}$ is then sufficient to trigger fault zone failure with an effective fault friction raised to $5^{\circ}$.

Moreover, in most models with configuration P2, the roof of the cavity and its overburden surface nearly always fail prior to fault zone failure, indicating that an eruption would likely result from the inflating cavity underneath. This means in turn that magmatic eruptions triggered by estimated overpressures of several tens of MPa, may also trigger failure of nearby upper crustal weak fault zones located within a $4 \mathrm{~km}$ distance - or more generally, located within a radial distance proportional to the average radius of the inflating magmatic source.

\subsection{Rheological parameters 'representativeness'}

The heterogeneities that we chose to model in the present study account for several combinations of both elastic and plastic properties, and the results show how both diffuse elastic dilation and localized plastic failure accommodate mechanical triggers. Numerous studies of the mechanical properties of rocks explore with laboratory experiments the factors that influence their values. Here we briefly review these studies, which justify the large range of plausible strength parameters that we have had to choose in our numerical models, given the lack of constraints available in our study area.

\subsubsection{Elastic modulus}

The estimation of a representative value of Young's modulus for the upper crust is a challenging task in volcano-tectonic modelling, because of its spatial and temporal variations, and because of the difficulties in upscaling laboratory or local field measured values to the rock mass scale. For such upscaling, works from Schultz (1996) or the more recent compilation study by Heap et al. (2020, and references therein) use geotechnical proxies such as RMR (Rock Mass Rating) and GSI (Geological Strength Index) respectively, to show that rock mass
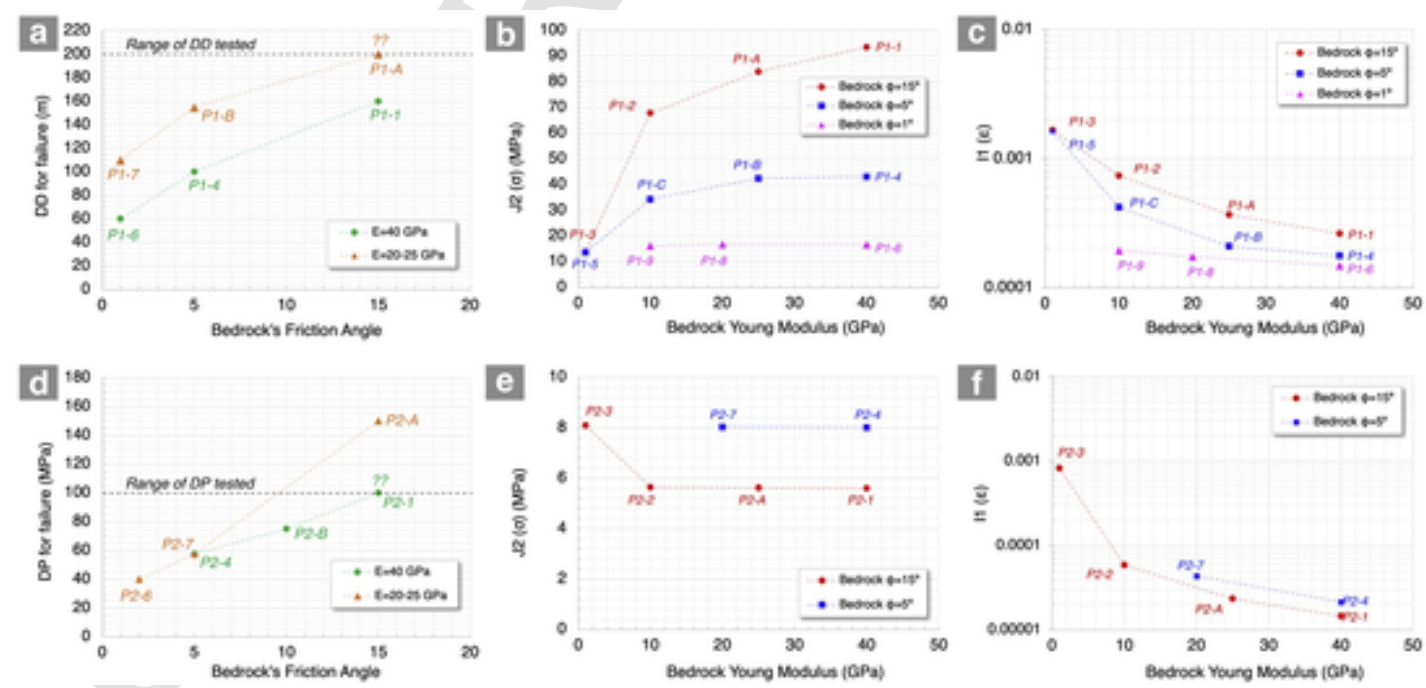

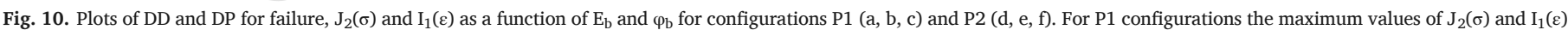

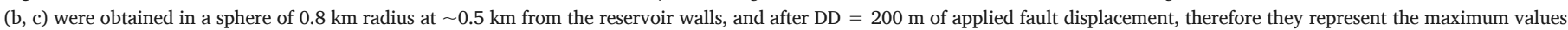

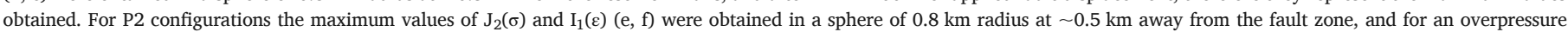

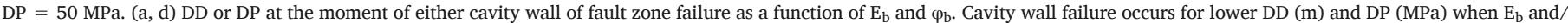

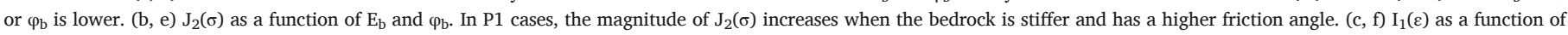

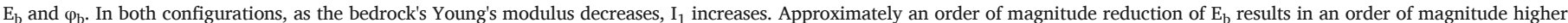
$\mathrm{I}_{1}(\varepsilon)$. 
Young's modulus, cohesive and tensile strength, can be reduced significantly relative to values for unfractured intact material. Elastic moduli, strength, porosity, and permeability are greatly influenced by the pre-existing fracture and pore network, and confining pressure. In volcanic rocks, low porosity rocks display a Young's modulus up to $50 \mathrm{GPa}$ while high porosity rocks display E lower than $1 \mathrm{GPa}$ (cf. Heap et al., 2020; Schaefer et al., 2015, Bubeck et al., 2017). At increasing confining pressures, the Young's modulus increases as microcracks are closed, as shown for instance experimentally by Villeneuve et al. (2018). Hydrothermal alteration increases or decreases rock stiffness by pore and micro crack filling or mineral dissolution alteration (e.g. Heap et al., 2020).

Rock masses and volcanic complexes are subjected to different strain rates and repeated cycles of stress, that lead to progressive damage and microcrack accumulation and tends to decrease the Young's modulus over time by 10 to 30\% (Kendrick et al., 2013; Heap et al., 2010). Modelling studies such as Got et al. (2017), proposed therefore the use of an effective Young's modulus as an exponential function of seismicity frequency and magnitude in the rock mass. Changes in temperature can also have an impact as thermal stresses and cracking are induced (e.g. Sepúlveda et al., 2020), especially in volcanic-hydrothermal systems. For several volcanic areas across Chile, a Young's modulus of 20 to $50 \mathrm{GPa}$ is often deduced from geophysical methods (e.g. Wendt et al., 2017; Novoa et al., 2019), which justifies our choice of $E_{b}$ values in the present study. However it is clear that the assumption of a uniform Young's modulus throughout the crustal domain calls for caution as it impairs the numerical determination of precise conditions for the onset of failure.

Estimating the equivalent elastic properties of a fault zone is also challenging. Numerous studies at the laboratory, outcrop, borehole and fault system scale, show a reduction in Young's modulus from the host rock to the fault core; Jeanne et al. (2017) show on outcropping limestone sites, a decrease from $42 \mathrm{GPa}$ to sometimes $6 \mathrm{GPa}$. Fialko (2004) estimated a reduction by $75 \%$ from GPS and INSAR measurements of the Landers earthquake. Here we adopted a minimal value $\mathrm{E}_{\mathrm{f}}$ of $1 \mathrm{GPa}$ from the calculation method proposed by Stanton-Yonge et al. (2020), by considering the $10 \mathrm{~km}$ linear dimension of the Melado fault. Our tested range of $E_{b}$ and $E_{f}$ Young's moduli aimed only at providing insights on the key relative values that facilitate or impede fault zone failure and rock mass deformation.

\subsubsection{Frictional strength}

The standard friction angle of crustal rocks is typically $30^{\circ}$, thoroughly verified since the major contributions by Coulomb or Byerlee. Nonetheless, countless studies recognize that friction heterogeneities appear with lithology, shear fabric and microstructure, pore fluid pressure, and other factors (e.g. Marone, 1995; Pola et al., 2014). For example, Hencher and Richards (2015) list values for clay infill less than $10^{\circ}$, and greater than $40^{\circ}$ for limestone or granite, all subject to great variation among samples. Pola et al. (2014) obtained friction angles between 20 and $30^{\circ}$ for lavas, $10-15^{\circ}$ for tuffs and ignimbrites, and a $45-85 \%$ loss in strength for altered lavas and pyroclastic rocks, leading to friction angles as low as $1.5^{\circ}-3^{\circ}$.

Weakening of crustal scale fault zones remains an intense subject of study, with mature crustal faults friction inferred to be $\sim 15^{\circ}$ or less (Rice, 1992). Several studies have proposed a clay content dependency in frictional properties of faults, with friction angles ranging between $1^{\circ}$ and $25^{\circ}$ (e.g. Saffer and Marone, 2003; Kenigsberg et al., 2020); others have shown that fabric such as very fine-grained foliations of phyllosilicates behave extremely weak and develop preferential frictional sliding orientations (Collettini et al., 2009; Saffer and Marone, 2003). Moreover, the seismogenic behavior of faults depends on their shear velocity, with smectite-rich clays and strong cleavages being able to rework shear structures and lead to dominantly aseismic shear, as opposed to younger fault rocks forming highly localized shear zones with velocity-weakening frictional behavior and seismic slip (Saffer and Marone, 2003).

The scale of the considered problem also appears as a key control on frictional strength. Studies of effective friction in accretionary wedges worldwide typically display values of thrust faults' effective friction as low as $0.1^{\circ}$ (e.g. Pajang et al., 2021). At the larger scale of subduction plate tectonics, numerical models also require effective frictions sometimes as low as $0.1^{\circ}$ in order to fit observations, such as for instance along the Chilean subduction zone on the scale of several Myr (e.g. Gerbault et al., 2009, and references therein), and for global scale terrestrial plate tectonics on the scale of Gyrs (e.g. Jain et al., 2019, and references therein). Along this line, the numerical models drawn here also question the way in which the concept of frictional strength can be extrapolated to the multi-kilometric crustal scale.

Pore fluid pressure also has a major influence on rock strength. Early on Rubey and King Hubbert (1959) formulated how pore-fluid pressure diminishes the effective normal stress thus lowering the frictional shear resistance. Cocco and Rice (2002) showed theoretically that fluid pressurization tends to cause expansion only in the fault-normal direction, and the concept of a pore-pressure dependent effective friction coefficient then applies well. While worldwide estimates lead to an average hydrostatic state of pore-fluid pressure (Zoback and Townend, 2001; Hillis, 2000), Suppe (2014) found that crustal frictional strength tends to become constant at depths greater than $2 \mathrm{~km}$ with values of 10 to $50 \mathrm{MPa}$, out of a worldwide compilation of deep borehole stress data. Here in the TSPVC, we could infer pore fluid pressures in excess of lithostatic from (1) the abundance of hydrothermal fault-vein systems and alteration zones (Fig. 1b), (2) the presence of the MGS and the numerous geothermal outflows, and from (3) the seismogenic activity of the Melado fault, consistent with seismogenic faulting occurring in association with zones of fluid overpressure (Sibson, 1990). According to this context, taking such a low value of friction angle as $0^{\circ}$ in our models, seems applicable.

As stated by Sibson (1994) and further contributions, fluid flow in tectonically active areas undergoes episodic perturbation on the time scale of several earthquakes (10-10.000 years), and is associated with transient lithostatic states of pore-fluid pressure up to $10 \mathrm{MPa}$ above hydrostatic (Terakawa et al., 2012). Cornet et al. (2007) explored micro seismicity induced by pore pressure variations during large-scale water injections in the experimental geothermal reservoir at Soultz (France); they report that induced seismicity can occur for small pore pressure variations, reflecting the "elastic" response to changes in local effective stresses. This latter situation may compare to our modelled diffuse domains of dilation in the intervening elastic bedrock domain.

\subsubsection{Tensile and cohesive strength}

Similarly, tensile and cohesive strength of a rock mass are significantly reduced, by as much as one or two orders of magnitude lower, when compared to laboratory measurements in intact rock, as strength and deformation strongly depends on the degree of fracturing and alteration (e.g. Schultz, 1996; Pola et al., 2014). For example, Schultz (1995) report from experimental results that $T$ and $C$ of basaltic rocks decreases from $14 \mathrm{MPa}$ and $66 \mathrm{MPa}$, to $0.1-2.5 \mathrm{MPa}$ and $0.6-6 \mathrm{MPa}$ when considering the weakening effects at a rock mass scale. Other authors have postulated that rock's cohesion and tensile strength are proportional to its Young's modulus (e.g. Zhan et al., 2019). However, we are not convinced that this linearity is systematic, hence we did not take it into account here.

\subsection{Significance of dilatational strain for the percolation of fluids}

Our numerical models show that dilatational domains develop at the edges of the major axis and above the magmatic reservoir, within 
the fault zone and in the intermediate bedrock domain, in both loading configurations. Within these domains, dilatational strain is in the order of $10^{-5}-10^{-3}$ over several cubic kilometers, proportional to the inverse of Young's modulus, values that are in accordance to the ranges evaluated for an influence on fluid mobilization (Manga et al., 2012; Ingebritsen and Appold, 2012). We infer that this dilation can be used as a proxy to the opening of pore space and/or distributed microcracking that increases the rock mass permeability (Simpson et al., 2001). However, how much exactly such stress-induced dilation can increase porosity and permeability remains difficult to assess because that relationship can be very non-linear (e.g. Nicolas et al., 2017; Got et al., 2017).

In the brittle and semi-brittle regime of deforming upper crustal rocks, Guéguen and Schubnel (2003) reviewed the key concepts of how cracks modify the fluid transport properties of rocks. Experimental results indicate that macroscopic fluid flow takes place through the crack network above a percolation threshold, while below, several percolative regimes may occur such as diffusive Darcy type linear or non-linear flow or porosity wave propagation (e.g. David et al., 1994). Rock permeability is well known to increase (non-linearly) with increasing porosity and to decrease with increasing effective pressure. Increasing permeability and fluid connectivity at the macro-scale enhances geofluid infiltration and the generation of fluid flow conduits from deeper crustal levels upwards (Sibson, 1994; Manga et al., 2012). Lamur et al. (2017) proposed an interesting equation linking the permeability of intact and fractured rocks with fluid flow in volcanic and geothermal systems. This would be a next step of confronting our numerical models with our field data.

In the field, geological expressions of a dilating volume would in clude dyke swarms, vein networks and dilatational breccias in fossil shear zones (e.g. Woodcock et al., 2006, Micklethwaite et al. 2014) and a combination of hot springs, distributed hydrothermalism, volcanic fissures and vents in active systems (e.g. Hill, 1977; Sielfeld et al., $2017,2019 b)$. Rock experiments show that dilation is a common precursor to fault initiation and propagation, with either shear or compaction bands then developing depending on the stress path and confining stress (Issen and Rudnicki, 2000; Guéguen and Bésuelle, 2007): under low confinement, brittle faulting tends to develop together with dilatant failure, whereas under high confinement, delocalized cataclasis is accompanied by shear-enhanced compaction and strain hardening (see review by Wong and Baud, 2012). At increasing depths towards the middle crust, melt draining processes come into play; from laboratory experiments Handy et al. (2001) argued that dilatant shear surfaces and vein networks serve as conduits for the rapid, buoyancy-driven ascent of transiently over pressured melt from melt-source rocks. However, according to these authors, acute weakening associated with strength drops of more than an order of magnitude occurs only during short periods (1-100 ky) of crustal-scale veining. Cooling and crystallization at the end of these veining episodes is fast and may then harden the crust to strengths sometimes greater than its pre-melting strength. Repeated melt-induced weakening then hardening of fault zones is very likely a major factor involved in transient stress transmission across orogenic magmatic arcs such as the SVZ.

\subsection{Fluid flow and fault rupture feedback at crustal scale}

Several authors have demonstrated that concentrated rupture and fluid flow occurs at dilatational jogs and wing-crack type fault terminations in strike-slip fault systems (e.g. Kirkpatrick et al., 2008). These observations have been assimilated with crustal earthquakes arising from fault propagation and arrest at geometrical singularities in which aftershocks concentrate (e.g. Micklethwaite and Cox, 2006). In our case study we have demonstrated a two-way link between faulting and an over pressurized fluid reservoir. On one side faulting may trigger significant dilation and fluid infill from a fluid reservoir (similar to the suction pump mechanism of Sibson, 1985) and even volcanic eruptions (Díez et al., 2005; Gregg et al., 2018), and on the other side fluid reservoir overpressure can, under certain circumstances, trigger fault slip in the form of an earthquake swarm (De Barros et al., 2019; Pearce et al., 2020) or of fault creep. Manga and Brodsky (2006) propose similar feedback processes for far field seismic triggering of volcanic eruptions, as earthquakes can induce unrest episodes in volcanic-geothermal systems through rapid and small changes in the stress field. In Southern Chile, the Mw 6.2 Aysén earthquake could be another good example of this local interplay. Legrand et al. (2011) wrote that "[...] this seismic swarm is a unique illustration of positive feedback between tectonic and volcanic activity, meaning that fluid movements may re-activate a tectonic fault, which may facilitate the movement of fluids and re-activate a volcanic-type seismic swarm in a self-organized feedback process".

\subsection{Interaction of regional tectonic loading and rates of tectono-magmatic processes}

Many studies relate the regional stress field and crustal deformation, and hence fluid flow, in different tectonic environments. In transpressive settings such as in the SVZ, oblique convergence results in deformation partitioning, which forms distinct tectonic domains in the continental margin where different fault geometries and kinematics accommodate the stress field (e.g. de Saint Blanquat et al., 1998; Stanton-Yonge et al., 2016). This in turn results in a strong structural control on Quaternary volcanism throughout the SVZ. The latter usually occurs in the form of (1) NE and NW volcanic alignments spatially associated with NE-striking oblique slip extensional faults and NW-striking inherited faults respectively, (2) spatially associated with $\sim$ NS-striking reverse faults and thrusts (between $33^{\circ}-36^{\circ} \mathrm{S}$ ) and (3) monogenetic and primitive volcanism spatially associated with the NNE-striking LOFS master fault (e.g. Cembrano and Lara, 2009).

In particular, the ENE-oriented TSPVC is the result of the long-term interaction of oblique and margin-parallel faults within the SVZ, and appears to be oriented sub-parallel to the maximum ENE-oriented interseismic shortening axis (Sielfeld et al., 2019b). Moreover, the geometry and kinematics of the Melado fault respond consistently to the regional stress field. Interestingly, although our models do not include the regional state of stress, they are capable to explain both the development of normal-dextral ENE-striking faults in the TDZ and dextral strike slip in the Melado fault by only taking into account the two-way interaction between a preexisting NNE-striking fault and a fluid reservoir located close to its northern termination. As a matter of fact, both the incremental displacement of a dextral NNE-striking fault and the inflation of an upper crustal reservoir, act consistently to promote the dilation of the rock volume in between them. This leads us to emphasize two key points reached from our models:

- First, both fault motion and magmatic inflation processes may be considered to occur simultaneously and continuously along the SVZ, especially over the several thousand years' time-scale, as shown for example by Galland et al. (2007). Hence, complementary models could show how their combination would enhance, by summation, the resulting dilatation and shear strain magnitude throughout the upper crust.

- Second, both fault displacement and magmatic inflation superimpose and actually counteract the effect of regional compression, which tends to generate shortening strain within the crust. Hence one next modelling step would be to evaluate how much of the obtained dilatation can occur when the regional transpressional stress field is taken into account. 
The models proposed were conceived precisely to concentrate on the meso-scale interactions between magma cavities and faults, rather than reproducing what is seen in this particular case study and tectonic setting. In this way, the models help deciphering which of the structural and hydrothermal features observed in the field might be directly linked to such interactions rather than to the regional far field stress.

\subsection{Implications for geothermal reservoirs}

Geothermal reservoirs here might be approximated by those diffuse domains that are able to sustain open pore spaces for a sufficient amount of geological time, thus around solicited strike-slip fault zones or above magmatic reservoirs. These diffuse domains could be sustained by the feeding from below of magmatic reservoirs, such as those detected by magnetotelluric studies. Even a slight increase in porosity and generation of secondary permeability through sub-scale micro-cracking and brecciation for example, over an area spanning several $\mathrm{km}^{3}$ may transform that area into hosting over-pressurized geothermal fluids originating from magmatic reservoirs located in the upper crust. In the TSPVC particularly, the volume and surface area of these diffuse domains hosting thermal manifestations is much larger than the conductive anomaly itself (Hickson et al., 2011), thus hinting the existence of more possibly smaller reservoirs within the region. Moreover, the stress state resulting from the models presented here, is compatible with the formation of levels of horizontal intrusions (e.g. sills) that could act as heat sources or store fluids (Fig. 7). Further integration of coupled fluid-flow and solid matrix deformation, together with resolution of the heat equation and basic chemical fluid reactions are required to further elaborate on the specific potential of the Mariposa geothermal field or similar geothermal reservoirs.

\section{Summary and conclusions}

1. We studied the interaction between a crustal strike slip fault and a crustal reservoir through numerical modelling. We tested tens of models that accounted for two loading conditions and different configurations of rheological parameters that give insight into the mechanical processes driving both localized and diffuse deformation throughout the crust and magmatic fluid transfer towards the surface.

2. Both the tectonic (fault displacement) and magmatic loading configurations create consistent dilation in the intermediate bedrock space to generate pathways for deep fluids to recirculate in the crust, and potentially reach the surface. This intermediate bedrock is spatially associated with the Mariposa Geothermal System. Future work should aim at understanding the effects of a regional transpression on the magnitude and geometry of this dilated rock volume.

3. From applying fault displacement (configuration 1), we conclude that tens to hundreds of meters of accumulated fault displacement can trigger sufficient shear stress to trigger magma reservoir failure within a lateral distance of $4 \mathrm{~km}$. If all displacement is regarded as accumulated seismic slip, $\sim 10^{1}-10^{2} \mathrm{Mw} 6-7$ earthquakes would be required to trigger this magma reservoir failure. However, most likely a combination of both seismic and aseismic slip is needed to achieve failure and open pathways for magmatic and hydrothermal fluids to the surface in timescales of several hundreds of years (e.g. $200 \mathrm{~m}$ at a rate of $\sim 2 \mathrm{~mm} / \mathrm{yr}$ ).

4. Bedrock Young's modulus is a determinant parameter for failure of the reservoir walls when looking at the perturbation generated by a local tectonic fault $\sim 4 \mathrm{~km}$ away. High stiffness allows for greater deviatoric stresses to propagate further away and hence trigger failure, as opposed to low bedrock stiffness that does not allow for the propagation of large deviatoric stresses.
5. From applying overpressure in the reservoir walls (configuration 2), we note that it is difficult for a $\sim 5 \mathrm{~km}$ wide shallow magma inflation to trigger fault displacement more than $4 \mathrm{~km}$ away, as it requires $>90 \mathrm{MPa}$ of pressure loading. However, a deep, mid-crustal magma inflation more easily breaks upper crustal faults, as only $\sim 10-20 \mathrm{MPa}$ of pressure loading are required to generate fault failure.

6. Bedrock friction angle is a determinant parameter for failure of the fault zone when looking at the stress changes due to reservoir inflation. A low bedrock friction allows the threshold-limited shear stress to propagate yet further away and reach the fault zone.

7. Dilatational domains appear naturally from the interaction between active oblique tectonics and inflating magmatic reservoirs, without needing to invoke other processes such as viscous compaction or crustal-scale extension. Mesoscale elastic dilation without rock failure is capable of opening pore space and appears efficient for fluid transfer.

8. Despite that precise values of rock Young's modulus and friction angle remain difficult to assess at such mesoscale, here we have shown that they control the magnitudes of diffuse and localized deformation. Future work should include two-phase flow modelling and model vs. field work comparisons in order to better estimate the volumes of fluid transfer, via diffuse vs. localized, volumetric and shear strain, to feed into geothermal potential and volcanic risk assessment.

\section{Uncited references}

Angermann et al., 1999

Novoa et al., 2021

\section{CRediT authorship contribution statement}

J. Ruz Ginouves: Conceptualization, Methodology, Software, Formal analysis, Investigation, Data curation, Writing - original draft, Writing - review \& editing, Visualization. M. Gerbault: Conceptualization, Methodology, Software, Validation, Formal analysis, Investigation, Resources, Data curation, Writing - original draft, Writing - review \& editing, Supervision, Funding acquisition. J. Cembrano: Conceptualization, Methodology, Validation, Formal analysis, Investigation, Resources, Writing - original draft, Writing - review \& editing, Supervision, Funding acquisition. P. Iturrieta: Conceptualization, Methodology, Software, Formal analysis, Investigation, Data curation, Writing review \& editing. F. Saez Leiva: Methodology, Software, Formal analysis, Investigation, Data curation, Writing - review \& editing. C. Novoa: Methodology, Formal analysis, Investigation, Writing - review \& editing. R. Hassani: Software, Resources, Writing - review \& editing.

\section{Declaration of Competing Interest}

The authors declare that they have no known competing financial interests or personal relationships that could have appeared to influence the work reported in this paper.

\section{Acknowledgements}

This research is supported by a Chilean-French scientific cooperation via the ECOS Project 180027/PC18U08, FONDAP project 15090013 CEGA (Centro de Excelencia en Geotermia de los Andes), and FONDECYT project 1141139 to J.C. The models were obtained thanks to the OMP Community Cluster Nuwa (http://www.aero.obs-mip.fr/parcinstru/platmod). The GMSH Gnu software was used to build the model's meshes (https://gmsh.info/) and ParaView was used for model analysis and visualization. We finally acknowledge the sub- 
stantial help by Leonardo Navarro-Valdivia with the 3D model results figures. We thank the editor, Dr. Diana Roman, and Journal referees Dr. Olivier Galland and an anonymous reviewer, whose comments significantly helped in improving this manuscript.

\section{Appendix A. Supplementary data}

Supplementary data to this article can be found online at https://doi. org/10.1016/j.jvolgeores.2021.107317.

\section{References}

Abdelmalak, M.M., Mourgues, R., Galland, O., Bureau, D., 2012. Fracture mode analysis and related surface deformation during dyke intrusion: results from 2D experimental modelling. Earth Planet. Sci. Lett. 359, 93-105.

Acocella, V., 2014. Structural control on magmatism along divergent and convergent plate boundaries: overview, model, problems. Earth Sci. Rev. 136, 226-288.

Acocella, V., Bellier, O., Sandri, L., Sébrier, M., Pramumijoyo, S., 2018. Weak tectono-magmatic relationships along an obliquely convergent plate boundary: Sumatra, Indonesia. Front. Earth Sci. 6, 3.

Angermann, D., Klotz, J., Reigber, C., 1999. Space-geodetic estimation of the Nazca-south America Euler vector. Earth Planet. Sci. Lett. 171, 329-334. doi:10.1016/ S0012-821X(99)00173-9.

Aravena, D., Muñoz, M., Morata, D., Lahsen, A., Parada, M.A., Dobson, P., 2016. Assessment of high enthalpy geothermal resources and promising areas of Chile. Geothermics 59, 1-13 Retrieved from http://www.sciencedirect.j.geothermics (2015.09.001).

Brogi, A., Liotta, D., Meccheri, M., Fabbrini, L., 2010. Transtensional shear zones controlling volcanic eruptions: the Middle Pleistocene Mt. Amiata volcano (inner Northern Apennines, Italy). Terra Nova 22, 137-146.

Bubeck, A., Walker, R.J., Healy, D., Dobbs, M., Holwell, D.A., 2017. Pore geometry as a control on rock strength. Earth Planet. Sci. Lett. 457, 38-48.

Cardona, C., Tassara, A., Gil-Cruz, F., Lara, L., Morales, S., Kohler, P., Franco, L., 2018 Crustal seismicity associated to rpid surface uplift at Laguna del Maule Volcanic complex, Southern Volcanic Zone of the Andes. J. Volcanol. Geotherm. Res. 353, 83-94. doi:10.1016/j.jvolgeores.2018.01.009.

Cembrano, J., Lara, L., 2009. The link between volcanism and tectonics in the southern volcanic zone of the Chilean Andes: a review. Tectonophysics 471 (1-2), 96-113. doi:10.1016/j.tecto.2009.02.038

Cembrano, J., Hervé, F., Lavenu, A., 1996. The Liquiñe Ofqui fault zone: a long-lived intra-arc fault system in southern Chile. Tectonophysics 259 (1-3), 55-66.

Cerpa, N.G., Araya, R., Gerbault, M., Hassani, R., 2015. Relationship between slab dip and topography segmentation in an oblique subduction zone: Insights from numerical modeling. Geophys. Res. Lett. 42, 5786-5795. doi:10.1002/2015GL064047.

Chéry, J., Zoback, M.D., Hassani, R., 2001. An integrated mechanical model of the San Andreas fault in central and northern California. J. Geophys. Res. 106 (B10), 22051-22066.

Cocco, M., Rice, J.R., 2002. Pore pressure and poroelasticity effects in Coulomb stress analysis of earthquake interactions. J. Geophys. Res. 107 (B2), ESE-2.

Collettini, C., Niemeijer, A., Viti, C., Marone, C., 2009. Fault zone fabric and fault weakness. Nature 462 (7275), 907-910.

Cornet, F.H., Bérard, T., Bourouis, S., 2007. How close to failure is a granite rock mass at a $5 \mathrm{~km}$ depth? Int. J. Rock Mech. Min. Sci. 44 (1), 47-66.

Cowie, P.A., Scholz, C.H., 1992. Displacement-length scaling relationship for faults: data synthesis and discussion. J. Struct. Geol. 14 (10), 1149-1156.

Cundall, P.A., Board, M., 1988. A microcomputer program for modeling large-strain plasticity problems. Num. Methods Geomech. 6, 2101-2108.

Currenti, G., Williams, C.A., 2014. Numerical modeling of deformation and stress fields around a magma chamber: Constraints on failure conditions and rheology. Phys. Earth Planet. Inter. 226, 14-27.

David, C., Wong, T.F., Zhu, W., Zhang, J., 1994. Laboratory measurement of compaction-induced permeability change in porous rocks: implications for the generation and maintenance of pore pressure excess in the crust. Pure Appl. Geophys. 143 (1-3), 425-456.

Davidson, J.P., Ferguson, K.M., Colucci, M.T., Dungan, M.A., 1988. The origin and evolution of magmas from the San Pedro-Pellado volcanic complex, S. Chile: multicomponent sources and open system evolution. Contrib. Mineral. Petrol. 100 (4), 429-445. doi:10.1007/BF00371373.

De Barros, L., Baques, M., Godano, M., Helmstetter, A., Deschamps, A., Larroque, C., Courboulex, F., 2019. Fluid-induced swarms and coseismic stress transfer: a dua process highlighted in the aftershock sequence of the 7 April 2014 earthquake (Ml 4.8, Ubaye, France). J. Geophys. Res. Solid Earth 124 (4), 3918-3932.

Dieterich, J.H., Smith, D.E., 2009. Nonplanar Faults: Mechanics of Slip and Off-fault damage. Pure Appl. Geophys. 166, 1799-1815. doi:10.1007/s00024-009-0517-y.

Díez, M., La Femina, P.C., Connor, C.B., Strauch, W., Tenorio, V., 2005. Evidence for static stress changes triggering the 1999 eruption of Cerro Negro Volcano, Nicaragua and regional aftershock sequences. Geophys. Res. Lett. 32, L04309. doi:10.1029/ 2004GL021788.

Ebmeier, S.K., Elliott, J.R., Nocquet, J.-M., Biggs, J., Mothes, P., Jarrín, P., Yépez, M., Aguaiza, S., Lundgren, P., Samsonov, S.V., 2016. Shallow earthquake inhibits unrest near Chiles-Cerro Negro volcanoes, Ecuador-Colombian border. Earth Planet. Sci. Lett. 450, 283-291. doi:10.1016/j.epsl.2016.06.046.

Ferrill, D.A., Winterle, J., Wittmeyer, G., Sims, D., Colton, S., Armstrong, A., Morris, A.P. 1999. Stressed rock strains groundwater at Yucca Mountain, Nevada. GSA Today 9 (5), 1-8.
Fialko, Y., 2004. Evidence of fluid-filled upper crust from observations of postseismic deformation due to the 1992 Mw7. 3 Landers earthquake. J. Geophys. Res. 109 (B8).

Galland, O., Hallot, E., Cobbold, P.R., Ruffet, G., de Bremond D'Ars, J., 2007. Volcanism in a compressional Andean setting: a structural and geochronological study of Tromen volcano (Neuquén province, Argentina). Tectonics 26 (4).

Galland, O., Holohan, E., de Vries, B.V.W., Burchardt, S., 2018. Laboratory modelling of volcano plumbing systems: a review. In: Physical Geology of Shallow Magmatic Systems. Springer, Cham, pp. 147-214.

Gerbault, M., 2012. Pressure conditions for shear and tensile failure around a circular magma chamber; insight from elasto-plastic modelling. Geol. Soc. Lond. Spec. Publ. 367 (1), 111-130.

Gerbault, M., Cembrano, J., Mpodozis, C., Farías, M., Pardo, M., 2009. Continental margin deformation along the Andean subduction zone: thermo-mechanical models. Phys. Earth Planet. Inter. 177, 180-205.

Gerbault, M., Hassani, R., Lizama, C.N., Souche, A., 2018. Three-dimensional failure patterns around an inflating magmatic chamber. Geochem. Geophys. Geosyst. 19, 749-771. doi:10.1002/2017GC007174.

Giambiagi, L., Ramos, V.A., 2002. Structural evolution of the Andes in a transitional zone between flat and normal subduction $\left(33^{\circ} 30^{\prime}-33^{\circ} 45^{\prime}\right.$ 'S), Argentina and Chile. J. S. Am. Earth Sci. 15, 99-114.

Gomila, R., Arancibia, G., Mitchell, T.M., Cembrano, J.M., Faulkner, D.R., 2016. Palaeopermeability structure within fault-damage zones: a snap-shot from microfracture analyses in a strike-slip system. J. Struct. Geol. 83, 103-120.

Got, J.L., Carrier, A., Marsan, D., Jouanne, F., Vogfjörd, K., Villemin, T., 2017. An analysis of the nonlinear magma-edifice coupling at Grimsvötn volcano (Iceland). J. Geophys. Res. 122 (2), 826-843.

Gregg, P.M., Le Mével, H., Zhan, Y., Dufek, J., Geist, D., Chadwick, W.W., Jr., 2018. Stress triggering of the 2005eruption of Sierra Negra volcano, Galápagos. Geophys. Res. Lett. 45. doi:10.1029/2018GL080393.

Grosfils, E.B., McGovern, P.J., Gregg, P.M., Galgana, G.A., Hurwitz, D.M., Long, S.M., Chestler, S.R., 2015. Elastic models of magma reservoir mechanics: a key tool for investigating planetary volcanism. Geol. Soc. London, Spec. Pub. 401 (1), 239-267.

Gudmundsson, A., 2006. How local stresses control magma-chamber ruptures, dyke injections, and eruptions in composite volcanoes. Earth Sci. Rev. 79 (1-2), 1-31.

Guéguen, Y., Bésuelle, P., 2007. Damage and localization: two key concepts in rock deformation studies. Geol. Soc. London, Spec. Pub. 289 (1), 7-17.

Guéguen, Y., Schubnel, A., 2003. Elastic wave velocities and permeability of cracked rocks. Tectonophysics 370 (1-4), 163-176.

Haberland, C., Rietbrock, A., Lange, D., Bataille, K., Hofmann, S., 2006. Interaction between fore-arc and oceanic plate at the south-central Chilean margin as seen in local seismic data. Geophys. Res. Lett. 33, 1-5. doi:10.1029/2006GL028189.

Handy, M.R., Mulch, A., Rosenau, M., Rosenberg, C.L., 2001. The role of fault zones and melts as agents of weakening, hardening and differentiation of the continental crust: a synthesis. Geol. Soc. London, Spec. Pub. 186 (1), 305-332.

Heap, M.J., Faulkner, D.R., Meredith, P.G., Vinciguerra, S., 2010. Elastic moduli evolution and accompanying stress changes with increasing crack damage: implications for stress changes around fault zones and volcanoes during deformation. Geophys. J. Int. $183(1), 225-236$.

M.J. HeapM. VilleneuveF. AlbinoJ.I. FarquharsonE. BrothelandeF. Amelung...P. BaudTowards more realistic values of elastic moduli for volcano modellingJ. Volcanol. Geotherm. Res.3902020106684

Hencher, S.R., Richards, L.R., 2015. Assessing the shear strength of rock discontinuities at laboratory and field scales. Rock Mech. Rock. Eng. 48 (3), 883-905.

Hickson, C.J., Ferraris, F., Rodriquez, C., Sielfeld, G., Henriquez, R., Gislason, T., Selters, J., Benoit, D., White, P., Southon, J., Ussher, G., Charroy, J., Smith, A., Lovelock, B. Lawless, J., Quinlivan, P., Smith, L., Yehia, R., 2011. The Mariposa geothermal system, Chile. Trans. - Geother. Resourc. Council 817-825.

Hill, D.P., 1977. A model for earthquake swarms. J. Geophys. Res. 82 (8), 1347-1352. doi:10.1029/jb082i008p01347.

Hillis, R., 2000. Pore pressure/stress coupling and its implications for seismicity. Explor. Geophys. 31 (2), 448-454.

Holohan, E.P., de Vries, B.V.W., Troll, V.R., 2008. Analogue models of caldera collapse in strike-slip tectonic regimes. Bull. Volcanol. 70 (7), 773-796.

Ingebritsen, S.E., Appold, M.S., 2012. The physical hydrogeology of ore deposits. Econ. Geol. 107 (4), 559-584.

Issen, K.A., Rudnicki, J.W., 2000. Conditions for compaction bands in porous rock. J. Geophys. Res. 105 (B9), 21529-21536.

Iturrieta, P., Hurtado, D., Cembrano, J., Stanton-Yonge, A., 2017. States of stress and slip partitioning in a continental scale strike-slip duplex: tectonic and magmatic implications by means of finite element modeling. Earth Planet. Sci. Lett. 473, 71-82.

Jain, C., Rozel, A.B., Tackley, P.J., Sanan, P., Gerya, T.V., 2019. Growing primordial continental crust self-consistently in global mantle convection models. Gondwana Res. 73, 96-122.

Jeanne, P., Guglielmi, Y., Rutqvist, J., Nussbaum, C., Birkholzer, J., 2017. Field characterization of elastic properties across a fault zone reactivated by fluid injection. J. Geophys. Res. 122 (8), 6583-6598.

Jeffery, G.B., 1921. IX. Plane stress and plane strain in bipolar coordinates. Philos. Trans. Roy. Soc. Lond. Ser. A 221 (582-593), 265-293.

Jellinek, A.M., DePaolo, D.J., 2003. A model for the origin of large silicic magma chambers: precursors of caldera-forming eruptions. Bull. Volcanol. 65 (5), 363-381.

Karaoglu, Ö., Browning, J., Bazargan, M., Gudmundsson, A., 2016. Numerical modelling of triple-junction tectonics at Karliova, Eastern Turkey, with implications for regional magma transport. Earth Planet. Sci. Lett. 452, 157-179. doi:10.1016/ j.epsl.2016.07.037.

Karaoglu, Ö., Browning, J., Salah, M.K., Elshaafi, A., Gudmundsson, A., 2018. Depths of magma chambers at three volcanic provinces in the Karliova region of Eastern Turkey. Bull. Volcanol. 80 (9), 69.

Kavanagh, J.L., Engwell, S.L., Martin, S.A., 2018. A review of laboratory and numerical modelling in volcanology. Solid Earth 9 (2), 531-571. 
Kendrick, J.E., Smith, R., Sammonds, P., Meredith, P.G., Dainty, M., Pallister, J.S., 2013. The influence of thermal and cyclic stressing on the strength of rocks from Mount St. Helens, Washington. Bull. Volcanol. 75 (7), 728.

Kenigsberg, A.R., Rivière, J., Marone, C., Saffer, D.M., 2020. Evolution of elastic and mechanical properties during fault shear: The roles of clay content, fabric development, and porosity. J. Geophys. Res. 125. doi:10.1029/2019JB018612.

King, G.C.P., Stein, R.S., Lin, J., 1994. Static stress changes and the triggering of Earthquakes. Bull. Seismol. Soc. Am. 84 (3), 935-953.

Kirkpatrick, J.D., Shipton, Z.K., Evans, J.P., Micklethwaite, S., Lim, S.J., McKillop, P., 2008. Strike-slip fault terminations at seismogenic depths: The structure and kinematics of the Glacier Lakes fault, Sierra Nevada United States. J. Geophys. Res. 113 (B4).

Lamur, A., Kendrick, J.E., Eggertsson, G.H., Wall, R.J., Ashworth, J.D., Lavall $\sqrt{ }($ e), Y., 2017. The permeability of fractured rocks in pressurised volcanic and geothermal systems. Sci. Rep. 7 (1), 1-9.

Lara, L.E., Lavenu, A., Cembrano, J., Rodríguez, C., 2006. Structural controls of volcanism in transversal chains: resheared faults and neotectonics in the Cordón Caulle-Puyehue area $\left(40.5^{\circ} \mathrm{S}\right)$, Southern Andes. J. Volcanol. Geotherm. Res. 158 (1-2), 70-86. doi:10.1016/j.jvolgeores.2006.04.017.

Lavenu, A., Cembrano, J., 1999. Compressional-and transpressional-stress pattern for Pliocene and Quaternary brittle deformation in fore arc and intra-arc zones (Andes of Central and Southern Chile). J. Struct. Geol. 21 (12), 1669-1691.

Le Corvec, N., McGovern, P.J., Grosfils, E.B., Galgana, G., 2015. Effects of crustal-scale mechanical layering on magma chamber failure and magma propagation within the Venusian lithosphere. J. Geophys.Res. 120 (7), 1279-1297.

Legrand, D., Barrientos, S., Bataille, K., Cembrano, J., Pavez, A., 2011. The fluid-driven tectonic swarm of Aysen Fjord, Chile (2007) associated with two earthquakes (Mw = 6.1 and $\mathrm{Mw}=6.2$ ) within the Liquiñe-Ofqui Fault Zone. Cont. Shelf Res. 31 (3-4), 154-161.

Liotta, D., Brogi, A., 2020. Pliocene-Quaternary fault kinematics in the Larderello geothermal area (Italy): Insights for the interpretation of the present stress field. Geothermics 83, 101714.

Manga, M., Brodsky, E., 2006. Seismic triggering of eruptions in the far field: volcanoes and geysers. Annu. Rev. Earth Planet. Sci. 34, 263-291.

M. MangaI. BeresnevE.E. BrodskyJ.E. ElkhouryD. ElsworthS.E. Ingebritsen...C.Y. WangChanges in permeability caused by transient stresses: field observations, experiments, and mechanismsRev. Geophys.5022012

Marone, C., 1995. Fault zone strength and failure criteria. Geophys. Res. Lett. 22 (6), 723-726.

McCaffrey, R., Zwick, P., Bock, Y., Prawirodirdjo, L., Genrich, J., Stevens, C., Puntodewo, S.S.O., Subarya, C., 2000. Strain partitioning during oblique plate convergence in northern Sumatra: geodetic and seismologi constraints and numerical modelling. J. Geophys. Res. 105, 28363-28376. doi:10.1029/1999JB900362.

Mescua, J.F., Giambiagi, L., Barrionuevo, M., Tassara, A., Mardonez, D., Mazzitelli, M., Lossada, A., 2016. Basement composition and basin geometry controls on upper-crustal deformation in the Southern Central Andes (30-36 S). Geol. Mag. 153 (5-6), 945-961.

Micklethwaite, S., Cox, S.F., 2006. Progressive fault triggering and fluid flow in aftershock domains: examples from mineralized Archaean fault systems. Earth Planet. Sci. Lett. 250 (1-2), 318-330.

Moeck, I., Kwiatek, G., Zimmermann, G., 2009. Slip tendency analysis, fault reactivation potential and induced seismicity in a deep geothermal reservoir. J. Struct. Geol. 31, 1174-1182.

Nakamura, K., 1977. Volcanoes as possible indicators of tectonic stress orientation principle and proposal. J. Volcanol. Geotherm. Res. 2 (1), 1-16.

Nicolas, A., Fortin, J., Guéguen, Y., 2017. Micromechanical constitutive model for low-temperature constant strain rate deformation of limestones in the brittle and semi-brittle regime. Geophys. J. Int. 211 (1), 300-321.

Novoa, C., Rémy, D., Gerbault, M., Baes, J.C., Tassara, A., Cordova, L., Cardona, C., Granger, M., Bonvalot, S., Delgado, F., 2019. Viscoelastic relaxation: a mechanism to explain the decennial large surface displacements at the Laguna del Maule silicic volcanic complex. Earth Planet. Sci. Lett. 521, 46-59. doi:10.1016/j.epsl.2019.06.005.

Novoa, C., Gerbautl, M., Remy, D., Cembrano, J., Lara, L., Ruz, J., Tassara, A., Baez, J.C., Hassani, R., Bonvalot, S., 2021. Activation of margin parallel shear zones favor explosive eruptions: could the Liquiñe-Ofqui Fault System promote the 2011 Cordon Caulle eruption?. Submitted to Earth Planet. Sci. Lett. Earth Planet. Sci. Lett. 521, 46-59.

Pajang, S., Cubas, N., Letouzey, J., Le Pourhiet, L., Seyedali, S., Fournier, M., Agard, P., Mahdi, Khatib M., Heyhat, M., Mokhtari, M., 2021. Seismic hazard of the western Makran subduction zone: insight from mechanical modelling and inferred frictional properties. Earth Planet. Sci. Lett. 562, 116789.

Pardo-Casas, F., Molnar, P., 1987. Relative motion of the Nazca (Farellon) and South American plates since late cretaceous time. Tectonics 6, 233-248.

R.K. PearceA. Sánchez de la MuelaM. MoorkampJ.O.S. HammondT.M. MitchellJ. Cembrano...N. Marshallinteraction between hydrothermal fluids and fault systems in the Southern Andes revealed by magnetotelluric and seismic dataEarth Space Sci.2020

Pérez-Flores, P., Cembrano, J., Sanchez, P., Veloso, E., Arancibia, G., Roquer, T., 2016. Tectonics, magmatism and paleo-fluid distribution in a strike-slip setting: Insights from the northern termination of the Liquiñe-Ofqui fault System, Chile. Tectonophysics 680, 192-210. doi:10.1016/j.tecto.2016.05.016.

Pérez-Flores, P., Veloso, E., Cembrano, J., Sanchez-Alfaro, P., Lizama, M., Arancibia, G., 2017. Fracture network, fluid pathways and paleostress at the Tolhuaca geothermal field. J. Struct. Geol. 96, 134-148. doi:10.1016/j.jsg.2017.01.009.

Piquer, J., Yañez, G., Rivera, O., Cooke, D.R., 2018. Long-lived crustal damage zones associated with fault intersections in the high Andes of Central Chile. Andean Geol. 46 (2), 223-239.

Pola, A., Crosta, G.B., Fusi, N., Castellanza, R., 2014. General characterization of the mechanical behaviour of different volcanic rocks with respect to alteration. Eng. Geol. $169,1-13$.
Reyes-Wagner, V., Díaz, D., Cordell, D., Unsworth, M., 2017. Regional electrical structure of the Andean subduction zone in central Chile $\left(35^{\circ}-36^{\circ} \mathrm{S}\right)$ using magnetotellurics. Earth Planets Space 69, 142-151. doi:10.1186/s40623-017-0726-z.

Rice, J.R., 1992. Fault stress states, pore pressure distributions and the weakness of the San Andreas fault. In: Evans, B., Wong, T.F. (Eds.), Fault Mechanics and Transport properties of Rock. pp. 475-503.

Rowe, C.D., Griffith, W.A., 2015. Do faults preserve a record of seismic slip: a second opinion. J. Struct. Geol. 78, 1-26.

Rowland, J.V., Sibson, R.H., 2004. Structural controls on hydrothermal flow in a segmented rift system, Taupo Volcanic Zone, New Zealand. Geofluids 4 (4), 259-283.

Rowland, J.V., Simmons, S.F., 2012. Hydrologic, magmatic, and tectonic controls on hydrothermal flow, Taupo Volcanic Zone, New Zealand: Implications for the formation of epithermal vein deposits. Econ. Geol. 107 (3), 427-457.

Rozhko, A.Y., Podladchikov, Y.Y., Renard, F., 2007. Failure patterns caused by localized rise in pore-fluid overpressure and effective strength of rocks. Geophys. Res. Lett. 34(22).

Rubey, W.W., King Hubbert, M., 1959. Role of fluid pressure in mechanics of overthrust faulting: II. Overthrust belt in geosynclinal area of western Wyoming in light of fluid-pressure hypothesis. Geol. Soc. Am. Bull. 70 (2), 167-206.

Ruz, J., Browning, J., Cembrano, J., Iturrieta, P., Gerbault, M., Sielfeld, G., 2020. Field observations and numerical models of a Pleistocene-Holocene feeder dyke swarm associated with a fissure complex to the east of the Tatara-San Pedro-Pellado complex, Southern Volcanic Zone, Chile. J. Volcanol. Geotherm. Res. 404, 107033.

Saffer, D.M., Marone, C., 2003. Comparison of smectite-and illite-rich gouge frictional properties: application to the updip limit of the seismogenic zone along subduction megathrusts. Earth Planet. Sci. Lett. 215 (1-2), 219-235.

de Saint Blanquat, Michel, Tikoff, Basil, Teyssier, Christian, 1998. Transpressional kinematics and magmatic arcs. Geol. Soc. Lond. Spec. Publ. SP135, 135. doi:10.1144/ GSL.SP.1998.135.01.21.

Schaefer, L.N., Kendrick, J.E., Oommen, T., Lavallée, Y., Chigna, G., 2015. Geomechanical rock properties of a basaltic volcano. Front. Earth Sci. 3, 29. doi:10.3389/ feart.2015.00029.

Schmiedel, T., Galland, O., Haug, Ø.T., Dumazer, G., Breitkreuz, C., 2019. Coulomb failure of Earth's brittle crust controls growth, emplacement and shapes of igneous sills, saucer-shaped sills and laccoliths. Earth Planet. Sci. Lett. 510, 161-172.

Schultz, R.A., 1995. Limits on strength and deformation properties of jointed basaltic rock masses. Rock Mech. Rock. Eng. 28, 1-15.

Schultz, R.A., 1996. Relative scale and the strength and deformability of rock masses. J. Struct. Geol. 18 (9), 1139-1149.

Sepúlveda, J., Arancibia, G., Molina, E., Gilber, J., Duda, M., Browning, J., et al., 2020 Thermo-mechanical behavior of a granodiorite from the Liquiñe fractured geothermal system (39 S) in the Southern Volcanic Zone of the Andes. Geothermics 87, 101828.

Sibson, R.H., 1985. A note on fault reactivation. J. Struct. Geol. 7 (6), 751-754. doi:10.1016/0191-8141(85)90150-6.

Sibson, R.H., 1990. Conditions for fault-valve behaviour. Geol. Soc. Lond. Spec. Publ. 54 15-28. doi:10.1144/GSL.SP.1990.054.01.02.

Sibson, R.H., 1994. Crustal stress, faulting and fluid flow. Geol. Soc. Lond. Spec. Publ. 78 (1), 69-84.

Sielfeld, G., Cembrano, J., Lara, L., 2017. Transtension driving volcano-edice anatomy: Insights from andean transverse-to-the-orogen tectonic domains. Quat. Int. 438, 33-49.

Sielfeld, G., Lange, D., Cembrano, J., 2019a. Intra-arc crustal seismicity: Seismotectonic implications for the southern Andes volcanic zone, Chile. Tectonics 38 (2), 552-578.

Sielfeld, G., Ruz, J., Brogi, A., Cembrano, J., Stanton-Yonge, A., Pérez-Flores, P., Iturrieta P., 2019b. Oblique-slip tectonics in an active volcanic chain: a case study from the Southern Andes. Tectonophysics 770. doi:10.1016/j.tecto.2019.228221.

Simakin, A.G., Ghassemi, A., 2010. The role of magma chamber-fault interaction in caldera forming eruptions. Bull. Volcanol. 72 (1), 85.

Simpson, G., Guéguen, Y., Schneider, F., 2001. Permeability enhancement due to microcrack dilatancy in the damage regime. J. Geophys. Res. 106 (B3), 3999-4016.

B.S. SingerR.A. ThompsonM.A. DunganT.C. FeeleyS.T. NelsonJ.C. Pickens...J. MetzgerVolcanism and erosion during the past $930 \mathrm{ky}$ at the Tatara-San Pedro complex, Chilean AndesGeol. Soc. Am. Bull.10921997127142

Souche, A., Galland, O., Haug, Ø.T., Dabrowski, M., 2019. Impact of host rock heterogeneity on failure around pressurized conduits: Implications for finger-shaped magmatic intrusions. Tectonophysics 765, 52-63.

Stanton-Yonge, A., Griffith, W.A., Cembrano, J., St. Julien, R., Iturrieta, P., 2016. Tectonic role of margin-parallel and margin-transverse faults during oblique subduction in the Southern Volcanic Zone of the Andes: Insights from Boundary Element Modeling. Tectonics 35 (9), 1990-2013. doi:10.1002/2016TC004226.

Stanton-Yonge, A., Cembrano, J., Griffith, W.A., Jensen, E., Mitchell, T.M., 2020. Self-similar length-displacement scaling achieved by scale-dependent growth processes: evidence from the Atacama Fault System. J. Struct. Geol. 133, 103993.

Suppe, J., 2014. Fluid overpressures and strength of the sedimentary upper crust. J. Struct. Geol. 69, 481-492.

Tapia, F., Farías, M., Naipauer, M., Puratich, J., 2015. Late Cenozoic contractional evolution of the current arc-volcanic region along the southern Central Andes (35²0'S). J. Geodyn. 88, 36-51. doi:10.1016/j.jog.2015.01.001.

Terakawa, T., Miller, S.A., Deichmann, N., 2012. High fluid pressure and triggered earthquakes in the enhanced geothermal system in Basel, Switzerland. J. Geophys. Res. 117 (B7).

Tibaldi, A., 2005. Volcanism in compressional tectonic settings: is it possible? Geophys. Res. Lett. 32. doi:10.1029/2004g1021798.

Tibaldi, A., Bonali, F.L., 2017. Intra-arc and back-arc volcano-tectonics: Magma pathways at Holocene Alaska-Aleutian volcanoes. Earth Sci. Rev. 167, 1-26.

Timoshenko, S., Goodier, J.N., 1970. Theory of Elasticity. 2nd ed. McGraw-Hill, New York, p. 608. 
Villeneuve, M.C., Heap, M.J., Kushnir, A.R., Qin, T., Baud, P., Zhou, G., Xu, T., 2018. Estimating in situ rock mass strength and elastic modulus of granite from the Soultz-sous-Forêts geothermal reservoir (France). Geothermal Energy 6 (1), 11.

Wendt, A., Tassara, A., Báez, J.C., Basualto, D., Lara, L.E., García, F., 2017. Possible structural control on the 2011 eruption of Puyehue-Cordón Caulle Volcanic complex (southern Chile) determined by InSAR, GPS and seismicity. Geophys. J. Int. 208 (1), 134-147.

Wong, T.F., Baud, P., 2012. The brittle-ductile transition in porous rock: a review. J. Struct. Geol. 44, 25-53.

Woodcock, N.H., Omma, J.E., Dickson, J.A.D., 2006. Chaotic breccia along the Dent Fault, NW England: implosion or collapse of a fault void? J. Geol. Soc. 163 (3), 431-446.

Zhan, Y., Gregg, P.M., Le Mével, H., Miller, C.A., Cardona, C., 2019. Integrating reservoir dynamics, crustal stress, and geophysical observations of the Laguna del Maule magmatic system by FEM models and data assimilation. J. Geophys. Res. 124 (12), 13547-13562.

Zoback, M.D., Townend, J., 2001. Implications of hydrostatic pore pressures and high crustal strength for the deformation of intraplate lithosphere. Tectonophysics 336 (1-4), 19-30. 